\title{
Measuring the long-distance accessibility of Italian cities
}

\author{
Paolo Beria $^{\mathrm{a}, *}$, Andrea Debernardi ${ }^{\mathrm{b}}$, Emanuele Ferrara ${ }^{\mathrm{b}}$ \\ a DAStU, Politecnico di Milano, Via Bonardi 3, 20133 Milano, Italy \\ b Studio META, Monza, Italy
}

\begin{abstract}

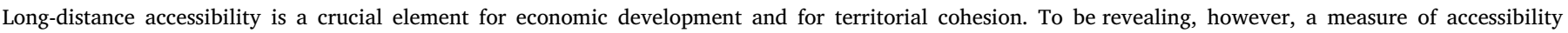
must not only consider the distance or travel time of a single mode, but should include the fares, the frequency and the interchanges of all available modes.

The paper aims to address whether and where there is an accessibility problem between Italian regions, through a comprehensive measure of accessibility

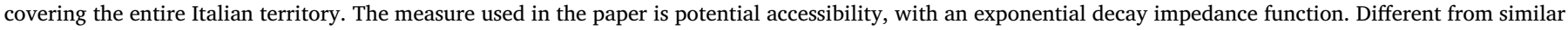

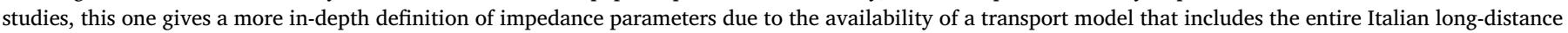

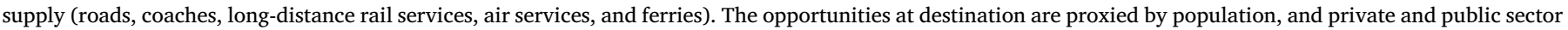
employees.

The main outputs are detailed maps of accessibility that are significantly more realistic than using simple infrastructure indicators or single-mode measures. In addition, some policy conclusions are drawn in terms of past and future investment policies.
\end{abstract}

\section{Introduction}

The detailed geography of Italian transport is barely known. Longdistance transport studies, such as ones similar to Eddington (2006) for the UK, simply do not exist. Official documents and statistics are always very aggregate (CNIT, 2013; ISTAT, 2013), and seldom accompanied by charts. The last national planning exercise dates back to 2001 (Ministero dei Trasporti, 2001), and was based on a highly aggregate description of networks and demand, but not supported by models. ${ }^{1}$

In all of these documents there is a constant, which is to firmly focus only on the infrastructural side of transport, practically ignoring demand and services. This is clearly unsatisfying when planning public transport or when assessing the effects of market liberalisation measures. Nonetheless, the Italian Ministry of Transport does make decisions involving significant financial investment on country-connectivity. Decisions are usually based on single-scheme studies, barely coordinated with other concurrent and competing projects (Beria et al., 2012) and relying only on the intuition that part of the country has difficult access to the core areas. The limitations to this approach are evident, possibly resulting in biased decisions, over-investment, underinvestment or simply inappropriate infrastructure design.

To overcome this unsatisfactory state, the paper aims to address whether and where there is a problem of long-distance accessibility to Italian regions, measured in a consistent way. While regional or local accessibility for Italy is sometimes studied (Lattarulo, 2009; De Montis et al., 2011; Cascetta et al., 2013) because more data is available at that scale and more interest is shown by the local authorities, the national dimension is barely known, with the relevant exception of Alampi and Messina (2011).

To do that, a detailed measure of potential accessibility for all of Italy has been built. The relative attraction power among cities is de-fined by population, private and public sector employees. Differently from most of previous applications, the impedance function is based on generalised cost instead of just travel time, thanks to a multimodal transport model that includes the entire Italian long-distance supply (roads, coaches, long-distance rail services, air services, and ferries). As most of the previous researches focus on single modes, the calculation of accessibility using multimodal measures is a challenging exercise (van Wee, 2016) and represents one of the main advancements of this work.

The paper is structured as follows. The next section will briefly introduce the geography of Italian transport, followed by Section 3, which revises the main accessibility indicators and comments on their meaning in terms of representativeness and consistency.

\footnotetext{
* Corresponding author.

E-mail address: paolo.beria@polimi.it (P. Beria).

${ }^{1}$ More in-depth, and sometimes also more detailed studies published by other subjects that are not connected to the Ministry of Transport are to be found (MCC, 2003; Banca d'Italia, 2011; Uniontrasporti, 2011), but the focus (infrastructure) and the data used (aggregated) are always the same.
} 

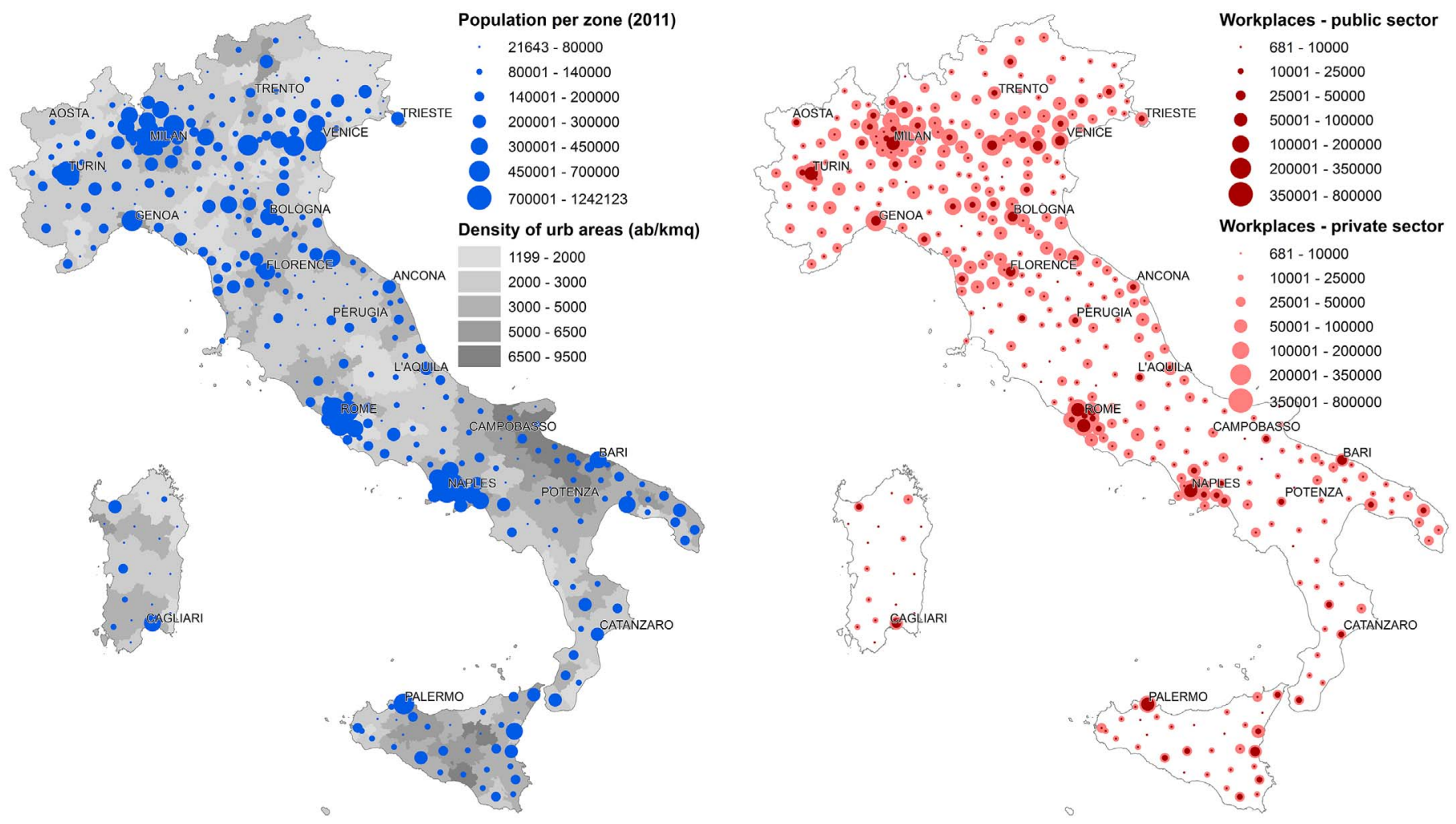

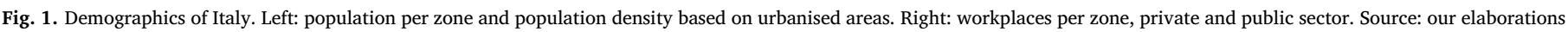
on 2011 census data.

Section 4 introduces the methodology and the data used, while Section 5 computes the accessibility for Italy according to the chosen definition and includes a sensiticity analysis. Based on these results, which are partially counter-intuitive because they reveal the complexity of the geography of such a large-scale transport system, the Section 6 will provide some policy indications and Section 7 will conclude.

\section{The geography of the Italian transport system}

\subsection{Population and cities}

The Italian population is almost totally urbanised. Urban areas, however, present very different characteristics and densities.

Fig. 1, left, illustrates the areas where most of the population is concentrated, namely the conurbations of Milan, Rome and Naples, also characterised by high densities. Venice, Bologna and Florence areas present lower densities, but relatively large populations. The other main cities (Turin, Palermo, Bari, and Catania) are more isolated.

The pattern of workplaces, as shown in Fig. 1, right, presents some differences. Workplaces are more concentrated in the north, where there is also a lower incidence of public sector employment. This entails a more concentrated pattern of work trips to provincial and regional capital cities, while manufacturing in the north tends to be spread outside of core cities.

\subsection{Transport supply}

The Italian infrastructure network comprises some $19,000 \mathrm{~km}$ of railways, more than $180,000 \mathrm{~km}$ of supra-local roads (Uniontrasporti, 2011) and several other local and urban roads. In addition, there are a hundred airports, 37 of which are used for commercial traffic, as well as 16 commercial ports (out of more than 200 other ports). Rail and main roads are unevenly distributed along the country. In the northern regions the network structure is reticular, while in the peninsular part mainly follows coastlines.

The infrastructure alone is not sufficient to explain how the Italian transport system "works". With the exception of private transport, the quantity and characteristics of services determine the level of supply.

A minimum level of rail supply exists over the entire country, with the exception of mountainous areas. The capillarity of such systems, however, is low and usually only the main settlements are served. Rail services and network connectivity are higher in the North than in the rest of the country. In central and southern Italy, and along the international corridors across the Alps, supply is almost completely concentrated on the main lines (Beria et al., 2015).

Focusing on long distance trains (Fig. 2), regional differences decrease, but services are limited to fewer main lines. Many secondary lines and stations do not have any long-distance service, thus reducing the penetration of rail in medium and low-density territories.

The coach services network is a totally different scenario. Coaches are concentrated in the south and in a handful of individual cities in the centre-north (Beria et al., 2014), as shown in Fig. 3, left. This network is a legacy from the past, when coaches were just a complement to absent or ineffective rail services. However, this is changing rapidly with the ongoing liberalisation process (Grimaldi et al., 2017).

Finally, Fig. 3, right, shows the supply of domestic flights in terms of daily frequencies (Mon-Fri average). Rome Fiumicino is the main Italian airport, but this dominance makes the rest of central Italy devoid of other airports. The main southern cities have a comparable supply (Catania is the largest), complemented by a few secondary airports. The situation in the north is more complex, due to high fragmentation. Milan is the main example, with three airports of comparable dimen-sion whose catchment areas partially overlap. This definitely increases the air accessibility of the served territories, but reduces the frequencies and sometimes the route sustainability as well. 


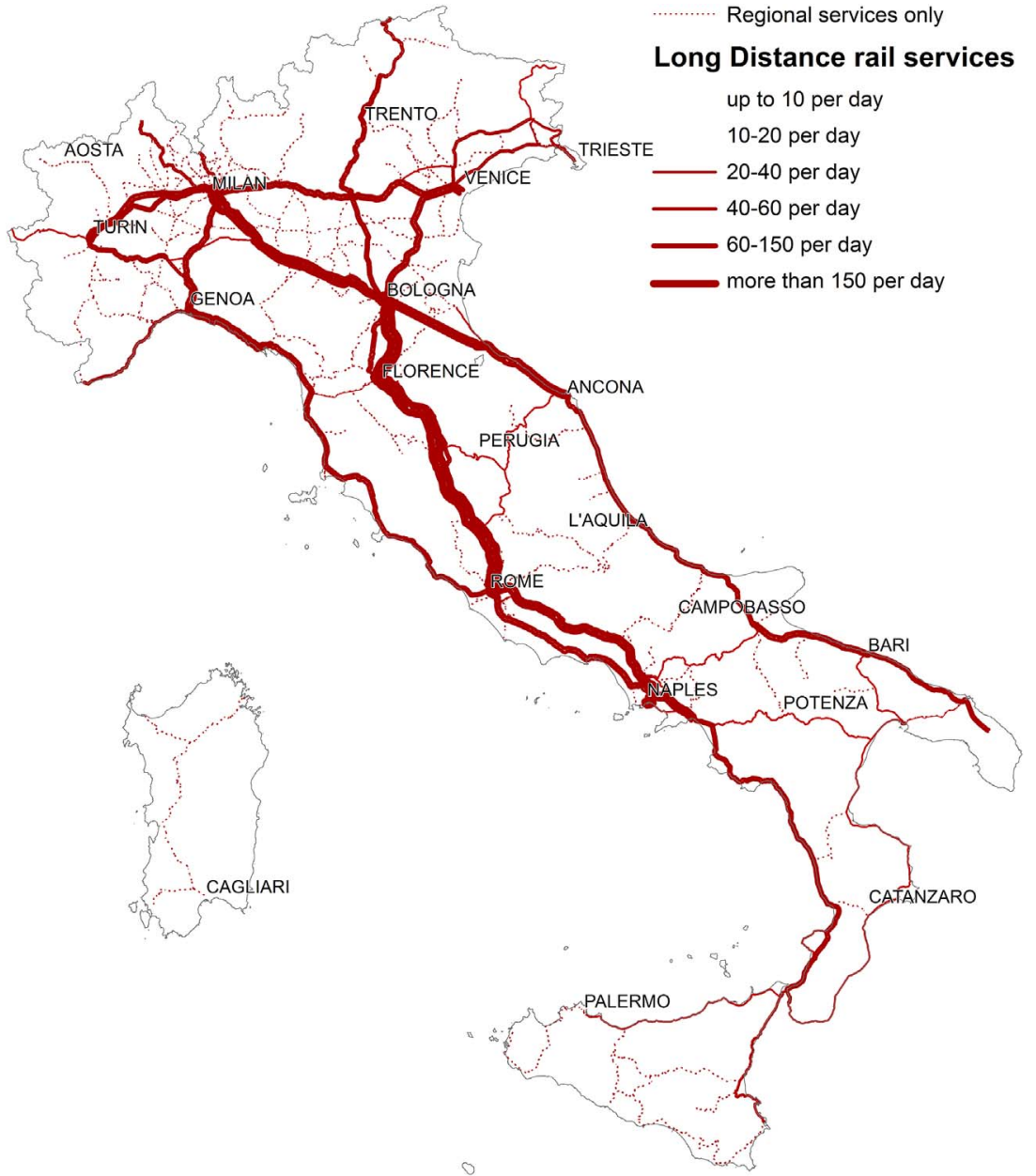

Fig. 2. Long-distance rail services supply (rides/day), 2014 timetable. Source: transport model I-TraM (META-TRASPOL).

\section{Accessibility measures}

\subsection{Classifying accessibility measures}

Accessibility is an intuitive concept, related to the ease of reaching a destination or accessing a service (van Wee, 2016). However, different definitions exist to formalise this concept, and the resulting indicators used are not fully comparable (Reggiani and Martín, 2011; Geurs et al., 2012). Moreover, some of the most complex indicators lack physical meaning, and thus accessibility should normally be intended as a relative measure and not as a characteristic of a place. In addition, the change in accessibility cannot be used in lieu of tools such as a costbenefit analysis for investment decisions. ${ }^{2}$

Notwithstanding these conceptual pitfalls, a properly designed accessibility measure can be useful to show how state-of-the-art an area is in terms of transport opportunities, to represent the effect of an investment or of a policy change, and, ultimately, to help decision-makers and planners understand the actual impact of their actions.

Several previous works revise and classify accessibility measures.

\footnotetext{
${ }^{2}$ This is based on two reasons: 1) accessibility depends on the definition used and extremely different results can be obtained; 2) accessibility only provides effectiveness (how accessibility is changed) and does not identify the efficiency of an action (i.e. how resources are used).
}

Handy and Niemeier (1997), Geurs and van Wee (2004), Martín and Reggiani (2007), Vandenbulcke et al. (2009) and Páez et al. (2012) are among the most complete reviews on the topic. According to the classification of Geurs and van Wee (2004), accessibility indicators belong to four groups, the simplest of which focuses on the physical performance of the transport system (infrastructure-based measures, such as network extensions or level of services). More complex indicators also consider the characteristics of the location or the opportunities at destination (location-based measures), or the characteristics of the individuals (person-based measures), or the economic benefit associated with access for individuals (utility-based measures). The first group's limit is that it only focuses on the transport side of the problem, ig-noring the purpose of the travel. The other measures are instead the-oretically coherent and also consider, respectively, land use, individual characteristics and utility of the trip. However, they are not directly intuitive.

\subsection{Location-based measures: Potential accessibility}

In this paper, we will use one formulation belonging to the locationbased measures, i.e. the potential accessibility:

$A_{i}=\sum_{j=1}^{n} M_{j} f\left(\beta, x_{i j}\right)$

where $A_{i}$ is the measure of accessibility from the origin $i, M_{j}$ is the 

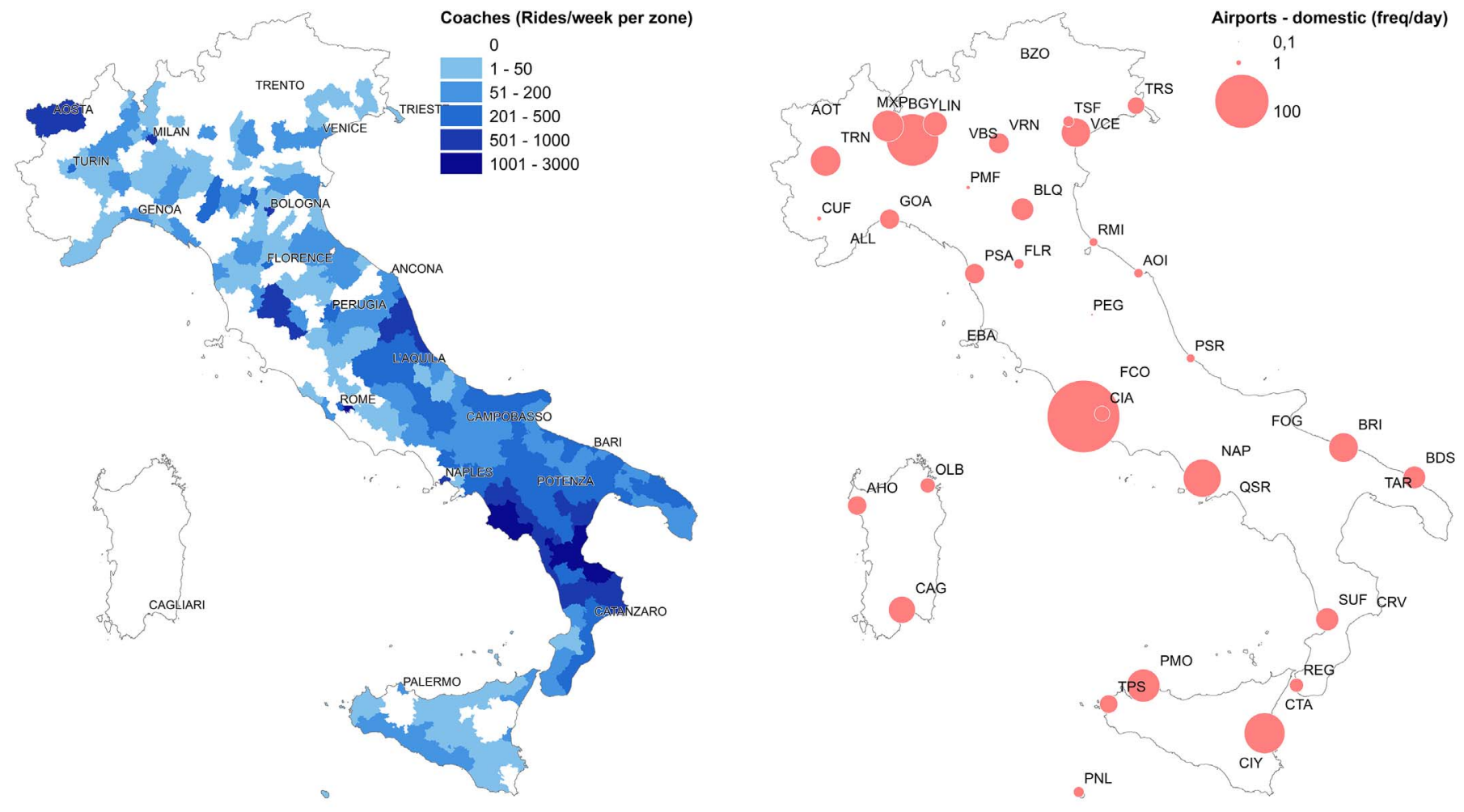

LMP

Fig. 3. Left: coach services supply (rides/week per zone), 2014 timetables. Right: domestic flight frequencies from Italia airports (frequencies/day), 2013 timetables. Source: transport model I-TraM (META-TRASPOL).

"mass" of opportunities at destination $j, \beta$ is the sensitivity parameter to $x_{i j}$, which is the impedance variable of the trip from $i$ to $j$. This formulation is general and both $M$ and $x$ can be declined differently. Typical variables used to proxy the attractiveness $M$ of the destination are: population, jobs, and GDP. Typical impedance variables are travel time, door to door time, distance, and generalised cost. The result Ai is usually normalised for readability, for example, around the average.

Also, the function $f$, called distance decay function, can take different formulations. Table 1 and Table 2 review the functions used in some of the country-wide accessibility studies found in literature.

Potential accessibility measures, like any other synthetic measure, have a number of limitations that must be taken into consideration: they depend on the study area (Ortega et al., 2012) and on the level of disaggregation (Handy and Niemeier, 1997; Vandenbulcke et al., 2009). The lack of physical meaning makes them "black-boxes", i.e. not easily interpretable by a third-party reader (Geurs and van Wee, 2004; Vandenbulcke et al., 2009). They usually consider one aspect only (e.g. rail accessibility to jobs) ${ }^{3}$ and ignore or misrepresent the intra-zonal accessibility (Geertman and Ritsema van Eck, 1995; Vandenbulcke et al., 2009; Condeço-Melhorado et al., 2016). ${ }^{4}$ Finally, as already mentioned, they ignore trade-offs and thus lack of economical meaning.

\subsection{Country-wide applications using an exponential decay function}

One of the most common formulations of distance decay functions is

\footnotetext{
${ }^{3}$ Building comprehensive indicators could be considered, for example, by "summing up" both population, GDP and jobs at destination, or weighting different modes (e.g. in Karampela et al., 2014), but this would risk decreasing the readability and comparability of the indicator, thus making it even more "black-box".

${ }^{4}$ Which also means that this could introduce a bias depending on the dimension and contents of the zones.
}

exponential decay. The resulting definition of potential accessibility is (Geertman and Ritsema van Eck, 1995):

$A_{i}=\sum_{j=1}^{n} M_{j} e^{-\beta x_{i j}}$

While most of the studies on accessibility are applied at the local level, only a few focus on the national scale. Table 2 revises the most recent ones and gives an idea of how different the models used can be, both for the indicator of the opportunities at the destination and the impedance variable.

With regard to the opportunities indicator, population of the destination zone is the most used measure because it is easier to collect, but it entails evident limitations. The first is that population is not a real indication of a destination's importance, especially if we are dealing with long-distance trips not for personal purposes. Business trips could be better proxied by GDP or by the number of jobs at the destination. Touristic importance depends on the number of beds. Student trips could be better described by the dimension of universities, and administrative-purpose trips depend on the administrative importance of the destination (as in Fransen et al., 2015). ${ }^{5}$

Similarly, the simplest impedance variable is the distance, but this does not describe the effect of different infrastructures, such as highspeed rail lines or motorways, with respect to zones that are similarly distant in space but not connected with the main networks. For this reason, most of the studies use travel time as an impedance variable. However, travel time ignores some relevant facts, such as the presence of congestion (Dewulf et al., 2015) or of competition (lowering prices on certain routes). Therefore, generalised cost (Koopmans et al., 2013)

\footnotetext{
${ }^{5}$ For example, all trips to ministries and embassies are necessarily directed to the capital city, whatever its dimension.
} 
Table 1

An example of accessibility studies, not using exponential decay functions.

\begin{tabular}{|c|c|c|c|c|c|}
\hline & Geography & Detail & Modes & Accessibility definition & Opportunities indicator $\mathrm{M}$ \\
\hline $\begin{array}{l}\text { Condeço-Melhorado et al. } \\
\text { (2011) }\end{array}$ & Spain & NUTS4 & Ro & $\Sigma_{\mathrm{j}}\left(\mathrm{Mj} / \mathrm{C}^{\alpha} \mathrm{ij}\right)$ & GDP, POP, JOBS \\
\hline $\begin{array}{l}\text { Duran-Fernandez and Santos } \\
\text { (2014) }\end{array}$ & Mexico & NUTS3 & & $\Sigma_{\mathrm{j}}\left(\mathrm{Mj} / \mathrm{T}^{\alpha} \mathrm{ij}\right)$ & $\begin{array}{l}\text { POP, JOBS (various), income } \\
\text { (various) }\end{array}$ \\
\hline $\begin{array}{l}\text { Geurs and Ritsema van Eck } \\
\text { (2003) }\end{array}$ & The Netherlands & M & Ro, PT & Log-logistic(Tij) & JOBS \\
\hline Gutiérrez and Urbano (1996) & $\mathrm{EU}$ & 98 cities & Ro & $\Sigma_{\mathrm{j}}(\mathrm{Tij} * \mathrm{Mj}) / \Sigma_{\mathrm{i}} \mathrm{Mj}$ & GDP \\
\hline Holl (2007) & Spain & $\mathrm{M}$ & Ro & $\Sigma_{\mathrm{j}}\left(\mathrm{Mj} / \mathrm{D}^{\alpha} \mathrm{ij}\right)$ & POP \\
\hline Jacobs-Crisioni et al. (2016) & $\begin{array}{l}\text { Austria, Czech Republic, Germany } \\
\text { and Poland }\end{array}$ & M & Ro & $\Sigma_{\mathrm{j}}\left(\mathrm{Mj} / \mathrm{C}_{\mathrm{ij}}\right)$ & POP \\
\hline Jiao et al. (2014) & China & $\begin{array}{l}\text { Prefecture }(\sim 330 \\
\text { zones })\end{array}$ & $\mathrm{Ra}$ & $\Sigma_{\mathrm{j}}\left(\mathrm{Mj} / \mathrm{T}^{\alpha} \mathrm{ij}\right)$ & $\sqrt{ } \mathrm{POP} * \mathrm{GDP}$ \\
\hline Karampela et al. (2014) & Greece & Islands & $\mathrm{A}, \mathrm{F}$ & $\begin{array}{l}\text { Access time from Athens including } \\
\text { frequency }\end{array}$ & n.a. \\
\hline Keeble et al. (1982) & $\mathrm{EU}$ & NUTS2 & n.a. & $\Sigma_{\mathrm{j}}(\mathrm{Mj} / \mathrm{Dij})$ & GDP \\
\hline Martín and Reggiani (2007) & $\mathrm{EU}$ & 88 cities & $\mathrm{Ra}$ & $\begin{array}{l}\Sigma_{\mathrm{j}}(\mathrm{Tij} * \mathrm{Mj}) / \Sigma_{\mathrm{i}} \mathrm{Mj} \\
\Sigma_{\mathrm{j}}\left(\mathrm{Mj} / \mathrm{D}^{\alpha} \mathrm{ij}\right) \\
\Sigma_{\mathrm{j}}(\mathrm{Mj} * \mathrm{f}(\mathrm{Tij}))\end{array}$ & GDP, POP \\
\hline Ortega et al. (2011) & Spain & M & Ro, Ra & Average effective speed & POP \\
\hline Ortega et al. (2012) & Spain & M & $\mathrm{Ra}$ & $\Sigma_{\mathrm{j}}\left(\mathrm{Mj} / \mathrm{T}^{\alpha} \mathrm{ij}\right), \alpha=1$ & POP \\
\hline Östh et al. (2015) & Sweden & M & n.a. & $\Sigma_{\mathrm{j}}\left(\mathrm{Mj} / \mathrm{D}^{\alpha} \mathrm{ij}\right)$ & JOBS \\
\hline Vandenbulcke et al. (2009) & Belgium & M & Ro, Ra & $\begin{array}{l}\text { Access time to towns and train } \\
\text { stations }\end{array}$ & n.a. \\
\hline Vickerman et al. (1999) & $\mathrm{EU}$ & 70,000 cells & $\mathrm{Ra}$ & $\Sigma_{\mathrm{j}}\left(\mathrm{Mj} / \mathrm{T}^{\alpha} \mathrm{ij}\right)$ & POP \\
\hline
\end{tabular}

Detail: the level of geographical disaggregation. M: municipality; NUTS2: regions; NUTS3: provinces; NUTS4: cluster of municipalities.

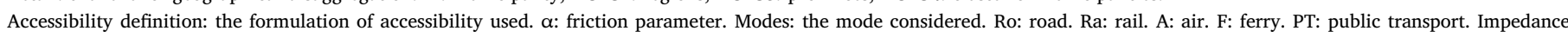
variable adopted. Cij: generalised cost. Tij: travel time. Dij: distance.

should be a more complete variable, but it is never used in the longdistance, most likely due to the complexity of its calculation.

Unfortunately, heterogeneous formulations make different studies hard to compare. Moreover, the beta used (calibrated or non-calibrated) are very different and thus consider places located at the same distance as differently accessible. The implications of beta will be discussed in Section 4.3.

\subsection{Exponential decay vs. negative power function}

Exponential decay function is one of the most used functions, but others exist. In particular, the negative power function is also used. The choice of the first one has some relevant consequences (Fotheringham and O'Kelly, 1989). Firstly, the parameter beta is not scale-independent and thus betas are not transferrable across studies. Secondly, it assumes a constant-decay parameter for all potential trip-makers (Choukroun, 1975). For this reason, one must rely on stylised traveller profiles (see below), that is homogeneous travellers for all origin-destination couples at short, mid or long distance. Thirdly, and most important, the negative power function would tend to infinite for low impedances while the exponential decay tends to one. This apparently makes the first more appropriate for long-distance studies (Fotheringham and O'Kelly, 1989), when nothing about local trips is modelled. However, in our model the spatial detail is high, especially in urbanised areas and consequently the range of variation of generalised costs is broad, making the use of a negative power function problematic.

\section{Methodology}

This work focuses on one of the accessibility measures described above, namely the potential accessibility, using an exponential decay function as in Eq. 2. We leave to sensitivity analysis (Section 5.4) the test of how the use of a negative power function would modify results.

The chosen measure has some relevant characteristics (Geurs and van Wee, 2004):

i. It takes the combined effect of land use and transport elements into account, the first represented by the number of opportunities $M_{j}$ at

Table 2

An example of accessibility studies, using an exponential decay impedance function $\mathrm{e}^{-\beta \mathrm{X} i \mathrm{j}}$

\begin{tabular}{|c|c|c|c|c|c|c|}
\hline & Geography & Detail & Modes & Opportunities indicator & Impedance variable $\mathrm{X}$ & $\beta$ value \\
\hline Alampi and Messina (2011) & Italy, EU & NUTS3 & Ro, Ra, A & Population & Dij, Tij & 0.005 \\
\hline Axhausen et al. (2011) & Switzerland & M & Ro, PT & Population & $\mathrm{Tij}$ & 0.2 \\
\hline Brödner et al. (2014) & $\mathrm{EU}$ & NUTS3 & Ro, Ra, A & Population & Tij & n.a. \\
\hline Bentlage et al. (2013) & Germany & NUTS3 & Ro, Ra, A & Firms & $\mathrm{Cij}$ & n.a. \\
\hline Dewulf et al. (2015) & Belgium (Flanders) & $\mathrm{M}^{* *}$ & Ro, Ra & Trips at destination & Tij & 0,041 \\
\hline Reggiani et al. (2011a) & Germany & M & Ro, Ra & Jobs & Tij & $0.008^{* * *}$ \\
\hline Rosik et al. (2015) & Poland & M & Ro & Population & Tij & $\begin{array}{l}0.005775 \text { (int), } 0.013862 \text { (nat), } 0.034657 \\
\text { (reg) }\end{array}$ \\
\hline Spiekermann and Schürmann (2007) EL & & NUTS3 & Ro, Ra & Population & Tij & 0.005 \\
\hline Stępniak and Rosik (2015)* & Poland (Mazovia) & M & & Population & Tij & 0.023105 \\
\hline
\end{tabular}

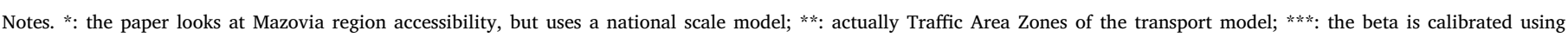
commuting trips only (i.e. without the other purposes, very relevant in the long-distance segment).

Detail: the level of geographical disaggregation. M: municipality; NUTS3: provinces.

Modes: the mode considered. Ro: road. Ra: rail. A: air. F: ferry. PT: public transport.

Impedance variable adopted. Cij: generalised cost. Tij: travel time. Dij: distance. 
destination and the second included in the variable of the decay function.

ii. The exponential decay function effectively represents individual

perception of distance, declining more than linearly. ${ }^{6}$

iii. The computation is not excessively complex, at least not implying recursive calculation.

Compared to previous studies, this study uses a more in-depth detail level of the impedance function, also including fares and interchanges, covering all transport modes, and being differentiated into two different travel purposes.

\subsection{The accessibility indicator used}

As opposed to most long-distance accessibility studies, we consider all components of generalised cost, as suggested by Koopmans et al. (2013), and not only time. The availability of a transport model, briefly described below, gives us the generalised cost $c_{i j}$ for all transport modes and for two different traveller profiles, also considering the actual level of supply (frequency of services and timetables) and the presence of competition through a simplified function of real-world fares.

In addition, three different measures of destination attractiveness are considered: population and private and public sector jobs, as pro-vided by the official Italian census (2011). The three measures are not alternatives, but represent three different travel purposes, where population may represent personal purpose trips, private sector jobs for business trips and public sector jobs for "administrative" trips, such as the broad range of visits to public offices, tribunals, hospitals and all trips typically attracted by administrative centres at various levels. ${ }^{7}$ This degree of detail in describing the attraction power of zones, seldom considered elsewhere, is present also in El-Geneidy and Levinson (2011).

The three equations used are:

Apop $_{i}=\sum_{j=1}^{n}$ Population $_{j} \cdot e^{-\beta c_{i j}}$

Ajob $_{i}=\sum_{j=1}^{n}$ Privatesectorjobs $_{j} \bullet e^{-\beta c_{i j}}$

$A p u b_{i}=\sum_{j=1}^{n}$ Publicsectorjobs $_{j} \bullet e^{-\beta c_{i j}}$

In addition, we also compute a more standard accessibility index, based on simple road distance, and more similar to the usual applications found in literature. It will be useful to compare its results, ignoring the shaping-space effect of transport, to the ones that take the transport supply characteristics into account.

Adist $_{i}=\sum_{j=1}^{n}$ Population $_{j} \cdot e^{-\beta d_{i j}}$

The combinations of modes and traveller purpose are illustrated in Table 3. All combinations are calculated directly with the mentioned equations, except for the multimodal one. In this case, the mode with the lowest generalised cost is preliminarily selected for each single origin-destination pair, and the overall accessibility of the $i$ zone is calculated by aggregating them. Therefore, for example, from a remote

\footnotetext{
${ }^{6}$ However, the use of other functions that are even more precise in the extreme ranges of near and far distances would be interesting for future applications. See Martínez and Viegas, 2013 or Halás et al., 2014.

7 Theoretically, it is possible to consider further splitting travel purposes, for example, by using university students, beds in hospitals, etc. to quantify the attraction power of zones. However, this could be too detailed and could lose generality and interest for a policy-level work. The circumstances would be different if we used an accessibility measure to build a distribution model to be calibrated.
}

Table 3

Combinations of modes and traveller profiles considered.

\begin{tabular}{lll}
\hline & Business travellers & Economy travellers \\
\hline Road & & \\
Rail & & \\
Air & - & \\
Coach & & \\
All modes & - & $\bullet$ \\
\hline
\end{tabular}

region, the overall accessibility is due to road accessibility for the nearest destinations and air accessibility for the farthest.

Once calculated, the $A_{i}$ are normalised by dividing the values found by the average value of the series, obtaining 100 for the zone with accessibility equal to the Italian average. Consequently, the nearest to 100 the values found are, the more the country is homogeneously accessible. As will be shown, the differences that exist are quite relevant.

\subsection{Transport model and generalised cost calculation}

While population and jobs are easily accessible data, generalised cost $c_{i j}$ must be computed using a transport model. The model is a conventional 4-step model, fed by a large supply database, developed by the authors and described in more detail in Beria et al. (2015).

The adopted zoning splits Italy into 371 zones. Each zone identifies a traffic catchment area that generally represents a homogeneous aggregation of municipalities based on their population. ${ }^{8}$

The supply module is primarily used for the calculation of generalised cost and includes:

- a multimodal graph, describing the Italian transport infrastructure in detail (rail network, road network, ports and the main maritime navigation routes, airports and air navigation routes) ${ }^{9}$;

- a timetable database, including the complete timetables for the year 2013-2014 for air, long-distance rail, coaches and main ferry service $^{10}$;

- a hypergraph of public transport services, linking together the timetable database and the multimodal graph.

- different functions for the fares, differentiated by competition level, distance travelled and/or advance of purchase, type of service (e.g. low-cost airlines' vs. traditional airlines; HS rail lines with direct competition are priced less than the rest of the Trenitalia network, etc.).

The generalised cost is estimated for two user profiles (business and economy), each having different values for travel time, private car availability and average stay in the place of destination.

The functions of generalised cost vary according to the mode, and are derived from the usual definitions (Ortúzar and Willumsen, 1990).

Private road transport cost is calculated for each road edge using the following formula:

$c_{c a r}=a D+b T+c P$

\footnotetext{
${ }^{8}$ This aggregation corresponds with the European statistical level NUTS-4 (European Commission, 2007) which, however, does not have a direct correspondence with any Italian administrative boundary (intermediate between single municipalities and provinces).

9 The multimodal graph includes five network classes, including information to describe the performances: national railway network (gauge, tracks, and module), national road network (subdivided into highway, provincial road and main connections at the subprovincial level), maritime and internal navigation network to provide continuity to land transport, air navigation routes (also including landside movement links), zonal and intermodal connectors.

${ }^{10}$ The database includes 12 air companies ( 6 low cost and 6 full service) operating 1300 routes, 2 rail companies (Trenitalia and NTV) operating 523 services on an average weekday and 80 coach companies operating 391 lines.
} 
$D$ is the distance (km). T is the time required to travel that distance on the basis of the average speed $(\mathrm{km} / \mathrm{h})$ allowed on that specific arc. $P$ is the toll, where applicable (typically on motorways). $a$ represents vehicle operating costs $(€ / \mathrm{km})$ and depends on the type of vehicle and, consequently, on the different user profiles (business, economy), $b$ is the value of time $(€ / \mathrm{h})$ and $c$ is the tariff perception (\%).

In the case of collective transport, the generalised cost formula becomes:

$c_{\text {publictransport }}=b T+c P$

Different from private transport, here $T$ is split into the waiting, access, travel and interchange times. $P$ is the fare for each O/D relation and is described through two components:

$P=p_{0}+p \cdot d$

where $d$ is the distance and $p$ is the price component proportional to distance, plus a fixed component independent from distance $p_{0}$. These parameters are empirically determined on a case by case basis.

Differently from local scale models, the timetable matters in long distance trips. For example, accessibility must be measured differently, especially for business travellers, if an air route with two flights per day is operated in the morning and in the evening between two cities or at, say, $11: 00$ and at 12:00.

For these reasons, the generalised cost used to calculate long-distance accessibility is computed for the entire day and not only for a (hardly definable) peak hour. Our assumptions on this are encompassed in Table 4.

\subsection{The beta parameter}

Accessibility definitions (Eq. 3 to Eq. 6) also include the parameter $\beta$, describing users' generalised cost sensitivity. For accessibility indicators expressed in exponential form, this parameter is directly derived from a trip generation function coherent with spatial entropy theory (Wilson, 1970, 1974). In short, $\beta$ describes the users' attitude to make a trip with different generalised costs, under the assumption of maximising the entropy of the system. As proofed by Leonardi (1985), the entropic expression of trip generation function is also asymptotically equivalent to a stochastic choice model, in which the users have to select only two basic options (travelling to destination or not). Therefore, $\beta$ parameter relates also with the direct elasticity of transport demand to the change of generalised costs on each O-D pair.

The parameter $\beta$ has a profound influence on the results. Values near to one rapidly reduce the influence of distant destinations and are the typical values used for commuters' accessibility. Using smaller values, instead, means that "distant" destinations are not irrelevant just because they are distant (for example, part of touristic trips does not decrease with distance).

Clearly, when studying long-distance trips, a small $\beta$ must be preferred. Using a too-large $\beta$ would in fact give just a map of the destination weight (for example, a map of the population), totally ignoring the effect of the transport-side in shaping accessibility.

Previous studies (in Table 2 and Table 5) use very different values.

Table 4

Rules for generalised cost calculation during the day, per mode.

\begin{tabular}{|c|c|c|}
\hline Mode & Rule & Periods \\
\hline Private, road & Daily average of best path generalised cost & 24 \\
\hline Public, coach & $\begin{array}{l}\text { Daily average of best path generalised cost, departing } \\
\text { per hour }\end{array}$ & 24 \\
\hline Public, air & $\begin{array}{l}\text { Daily average of best path generalised cost, departing } \\
\text { per hour }\end{array}$ & 24 \\
\hline Public, rail & Best path generalised cost, departing at 7:00 & $1^{\mathrm{a}}$ \\
\hline
\end{tabular}

${ }^{\text {a }}$ Most rail services are organised with clock-faced timetables, i.e. repeated during the whole day.
Moreover, none of the consulted sources applies generalised cost impedance functions and, consequently, their values cannot be transferred to this study. Therefore, we refer to $\beta=0.01$, which is sufficient to effectively point out the differences among zones. ${ }^{11}$

\section{Results}

\subsection{Distance-based indicators: A measure of remoteness}

Accessibility calculated by using the road distance as an impedance function shows the broadest differences (see Fig. 4, left). Italy's geography, being long and thin and with the two coasts separated by mountains, together with the distribution of the population concentrated in the northern plain or along the coasts, translates into very inhomogeneous situations. In the north, a large population lives relatively concentrated in a plain territory. In the south, only Rome and Naples have an above-average indicator due to their dimensions and vicinity. Overall, Italy looks divided in three accessibility areas: the north, compact and populated, the dipole of Rome and Naples, and the rest of the centre-south, spread or scarcely populated, at least in relative terms.

Accessibility weighted by workplaces and public-sector workplaces (not represented), instead of population, gives slightly different results. In particular, when looking at private sector workplaces, the whole south always falls below the average. This is due to the lower number of workplaces existing in the lower range of distances. To the contrary, the number of public sector employees is more than proportional to the population and, consequently, accessibility is higher and larger parts of the south are above the average. Assuming the number of public sector employees as a proxy for the public functions, this means that the physical remoteness of the southern areas from administrative centres and public services (hospitals, office, etc.) is less problematic than the one from economic activities.

\subsection{Generalised cost-based indicators: A measure of real accessibility}

Distance alone only deals with the geographic remoteness of an area from the rest of the destinations and does not identify real accessibility. Using the generalised travel cost as an impedance function, and considering the best mode to reach destinations, can significantly change the accessibility map, bringing it closer to real transport choices. Generalised cost perception is also different between "Business" travellers, i.e. more time-sensitive and less price-sensitive, and "Economy" ones, i.e. with inverted cost perceptions and without the availability of a private car for long-distance travels (as defined in Section 4).

Fig. 4, centre and right charts, depicts the generalised cost accessibility for both user categories according to 2013-2014 public transport timetables. The "Business" category shows some relevant differences with respect to distance-based accessibility charts. For example, due to their effective connections, cities such as Florence and Rimini are significantly more accessible if not just considering distance. Similarly, the transport network (rail and motorways) and air services make the southern areas slightly less inaccessible, partially overcoming geographical constraints.

The main transport corridors are clearly visible on the map, especially the Milan - Rome - Naples one: the old A1 motorway, the conventional rail line and the new high-speed line make cities along this corridor definitely more accessible than the average, creating a sort of continuum, irrespective of actual distances. Also, the gap of southern regions of Sicily, Sardinia, Calabria and Apulia decreases with respect to the northern areas thanks to road and air transport. Inaccessible

\footnotetext{
${ }^{11}$ The value, however, is not calibrated (this would be virtually impossible since no long-distance origin-destination matrix that also includes non-systematic trips exists for Italy), and thus only has a visualisation purpose.
} 
Table 5

Exponential decay function parameters, from Rosik et al., 2015.

\begin{tabular}{|c|c|c|c|}
\hline Authors & Spatial scale & $\beta$ parameter & Details \\
\hline Stępniak and Rosik (2013) & European & 0.005775 & Cars \\
\hline Schürmann and Talaat (2000) & European & 0.007 & Cars \\
\hline Schürmann et al. (1997) & European & 0.010 & Cars \\
\hline Reggiani et al. (2011b) & National & 0.009 & Commuters in Germany \\
\hline Stępniak and Rosik (2013) & National & 0.023105 & Population \\
\hline Stępniak et al. (2013) Geurs & National & 0.034657 & Population \\
\hline and Van Eck (2001) & National & 0.039 & Dutch National Travel Survey \\
\hline Spiekermann et al. (2014) & National & 0.04621 & Medical doctors \\
\hline Skov-Petersen (2001) Martínez & National & 0.049 & Recreational accessibility in Denmark \\
\hline and Viegas (2013) Handy and & Regional/local & 0.068 & Lisbon Metropolitan Area \\
\hline Niemeier (1997) Haynes et al. & Regional/local & 0.1813 & Convenience shopping travel in the San Francisco Bay Area \\
\hline (2003) & Regional & 0.289 & General medical practise surgeries in East Anglia \\
\hline
\end{tabular}

areas for the business segment are now limited to the most insular and peninsular areas (for example the city of Crotone). In very simplistic terms, the Italy of business travellers is divided in two, yet the division is not between the north and south, but across the Apennine mountains: the north, Tuscany region, and the cities of Rome and Naples are above the average, while the rest of the country is below, even in a centrenorth region like the Marche.

When considering "Economy" travellers, we only consider public transport (no private car) and the value of time is far less than for business travellers. The outlook changes again and portrays a significantly more homogeneous country. In particular, the North's relative advantage decreases and the most accessible area is that around the city of Bologna, which is the true centre of the Italian rail and coach networks.

\subsection{Single-mode accessibility}

The examination of single-mode accessibility rather than multimodal can clarify the different roles that air, coach and rail play in shaping Italian mobility patterns.

Not surprisingly, air transport patterns (Fig. 5, left and centre) are discontinuous. The areas of higher accessibility are around the main airports, and the rest lay below. The role of air transport is particularly important for islands. For example, point-to-point routes of low cost airlines, make Sicilian main cities more accessible than many important centres of the north, such as Genoa. Milan appears less accessible by air than several other areas, because of higher airport access cost and because of a relatively limited domestic network (both due to the Alitalia de-hubbing of 2008 and the opening of the high-speed rail line). Central Italy is the least accessible area by air. This is due to the relative proximity to Rome, whose airports centralise nearly all the traffic of the

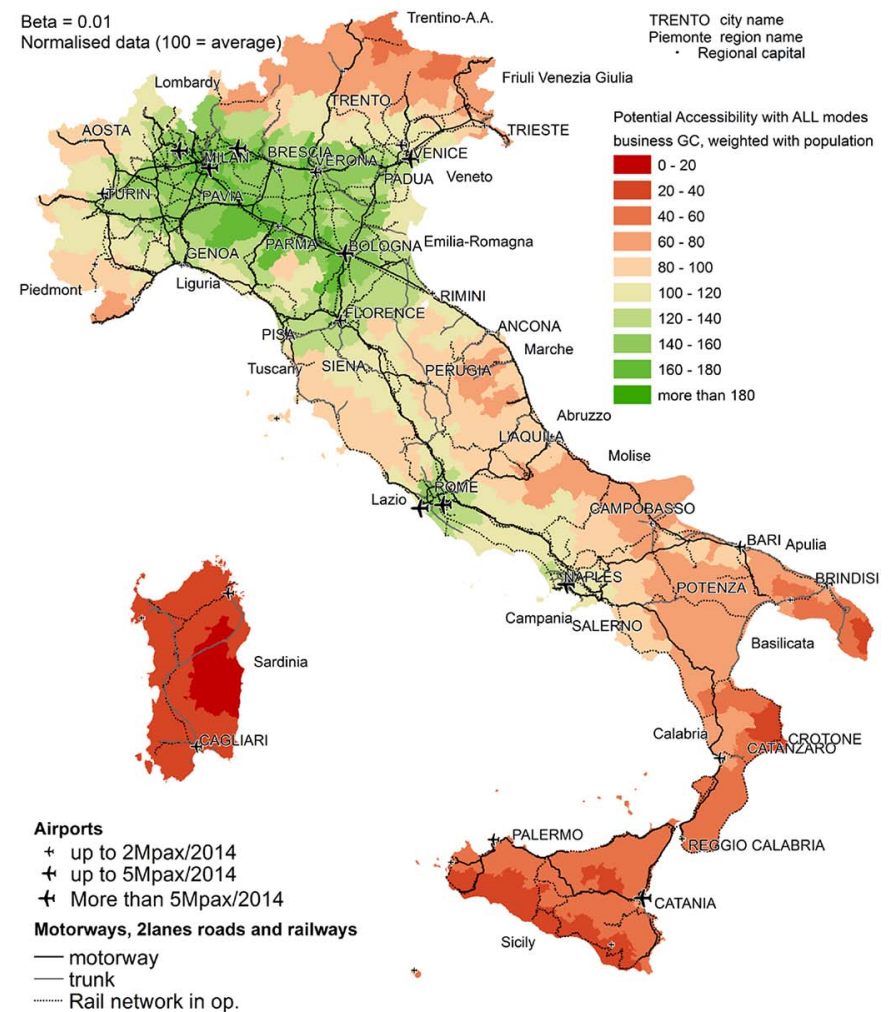

........ Rail network in op.

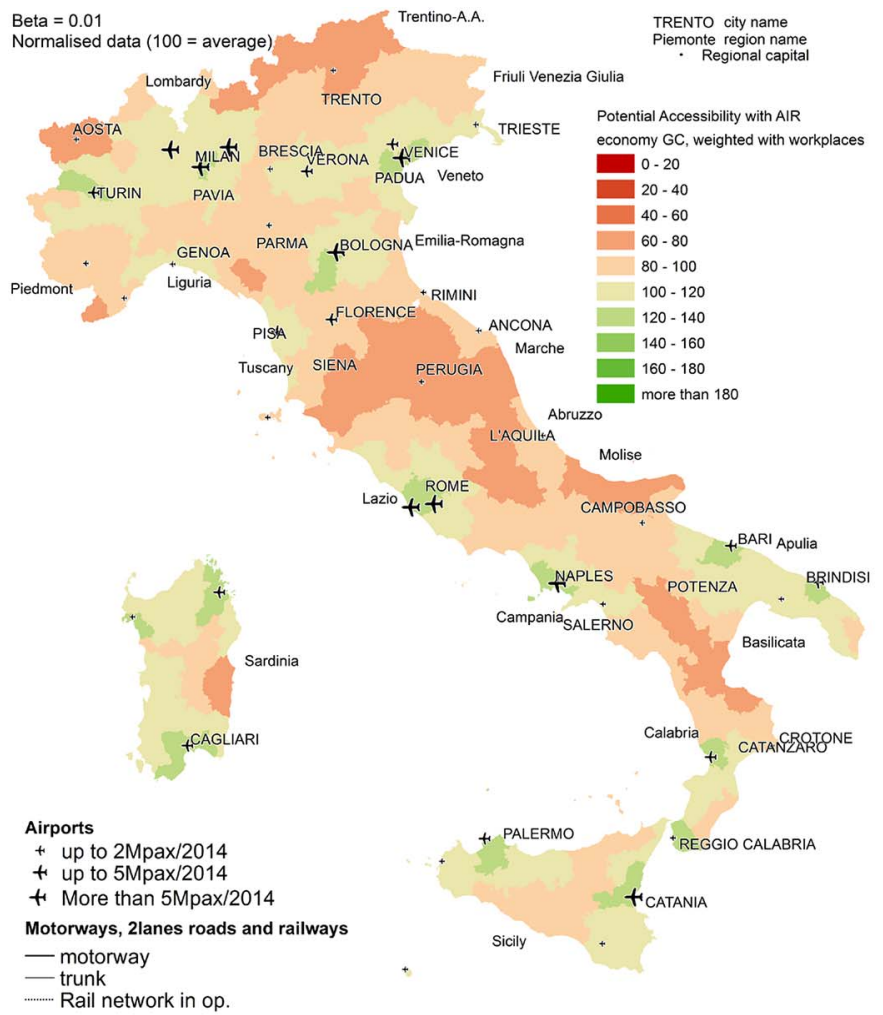

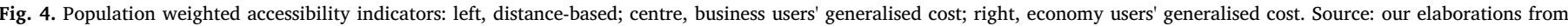
transport model I-TraM (META-TRASPOL), based on 2013-2014 timetables. 


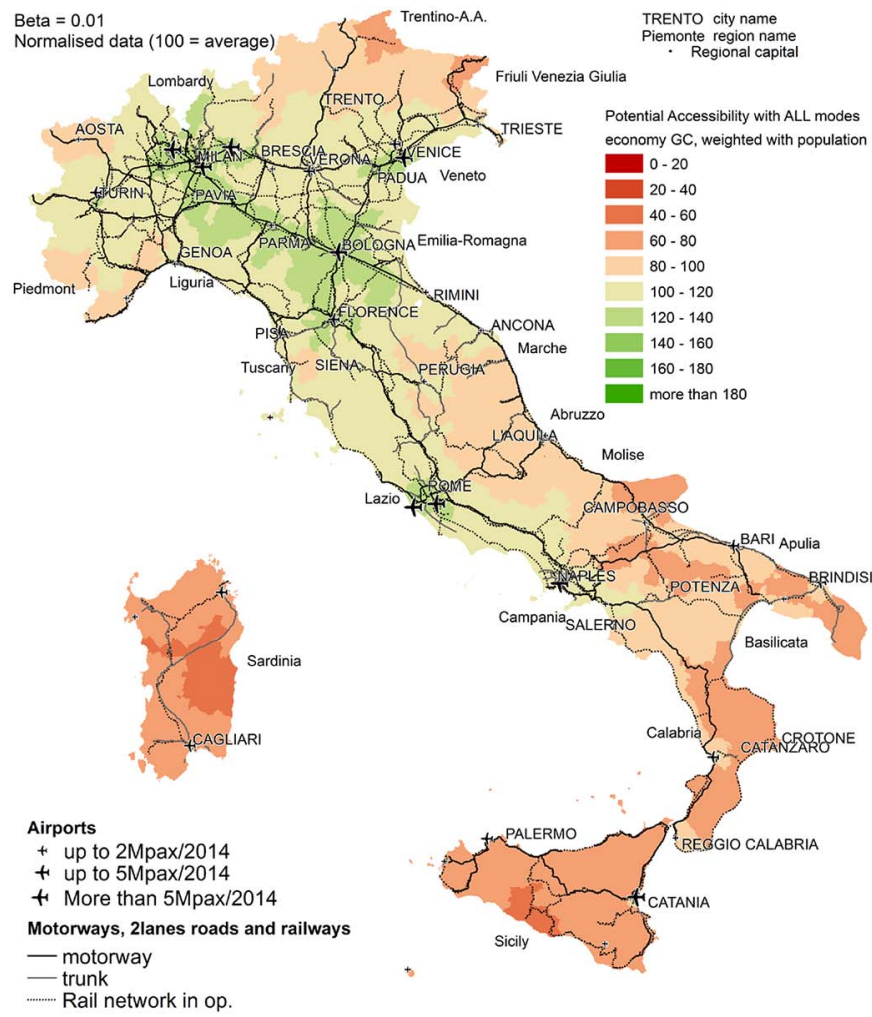

Fig. 4. (continued)

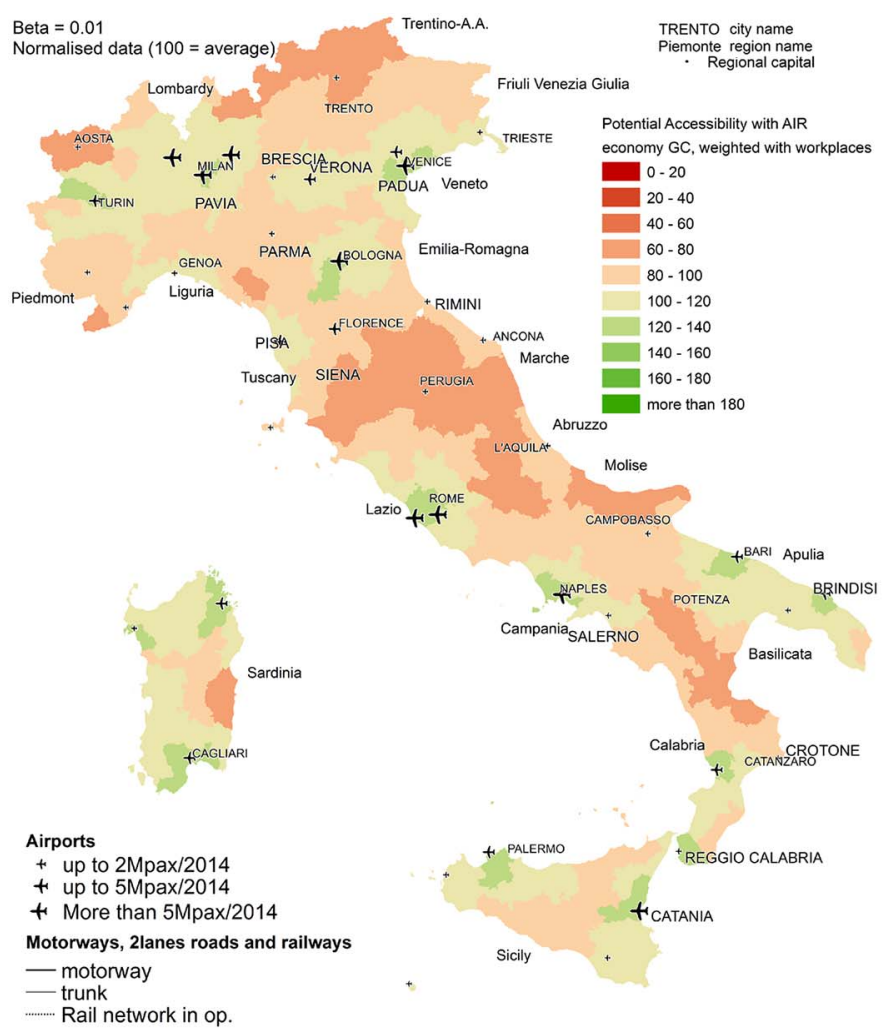

area, and to the type of distance (4-500 km) which separates the area from Italy's main cities, making it unsuitable for air transport.

Coach transport is a niche mode, mostly used by Economy users in specific areas of the country, usually where no good rail transport is available. The chart in Fig. 5, right, shows where the coach market core lies: limited in the north, much more developed in the centre and south, and especially directed towards Siena, Rome and Naples (Beria et al., 2014). In line with other countries (Augustin et al., 2014), this is rapidly changing due to the recently-finalised liberalisation and to the new lines in the North have opened in competition to rail.

Finally, rail is analysed in the Fig. 6 charts. The left chart again demonstrates a double-faced country. The northern regions and the western coast up to Salerno are highly accessible (except the mountains), also as a result of the recently opened high-speed line connecting Milan and Naples $(800 \mathrm{~km})$ in about $4.5 \mathrm{~h}$. The rest of the south and a long stretch of the eastern coast lay below the average, due to slower services, together with a smaller and sprawled population. Central Italy appears to be less accessible than the national average. Again, Business users have a different perception of the value of time and this makes the respective maps sharper. In addition, main cities are much more accessible than other areas, a consequence of the increasing polarisation of rail traffic on fewer high-frequency intercity connections.

\subsection{Sensitivity analysis}

All results depend on two important assumptions made, as documented before: the use of the exponential decay function and the value of the beta parameter. This section will comment the effect of both of them through a sensitivity analysis.

The use of a negative power function in spite of the exponential decay one has already been commented in Section 4. With respect to the original function, the negative power is more extreme in its scale effect,

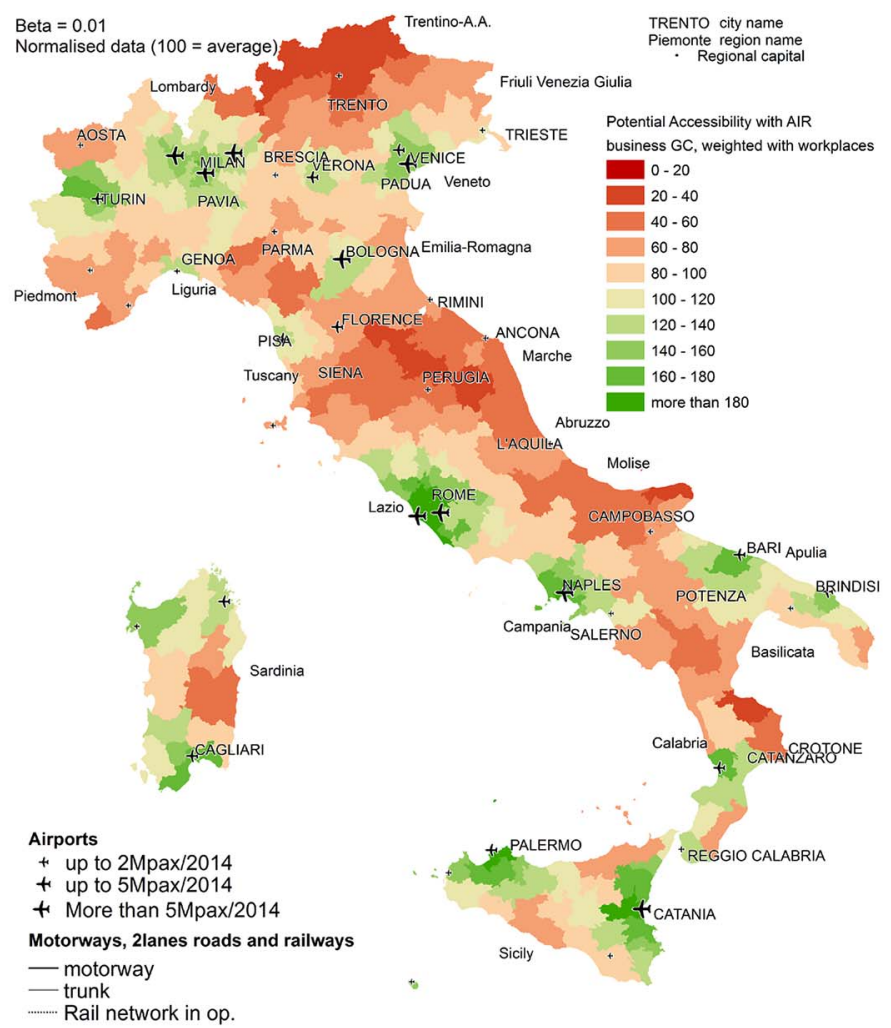

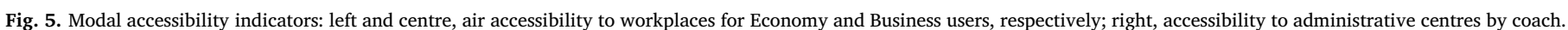
Source: our elaborations from transport model I-TraM (META-TRASPOL), based on 2013-2014 timetables. 


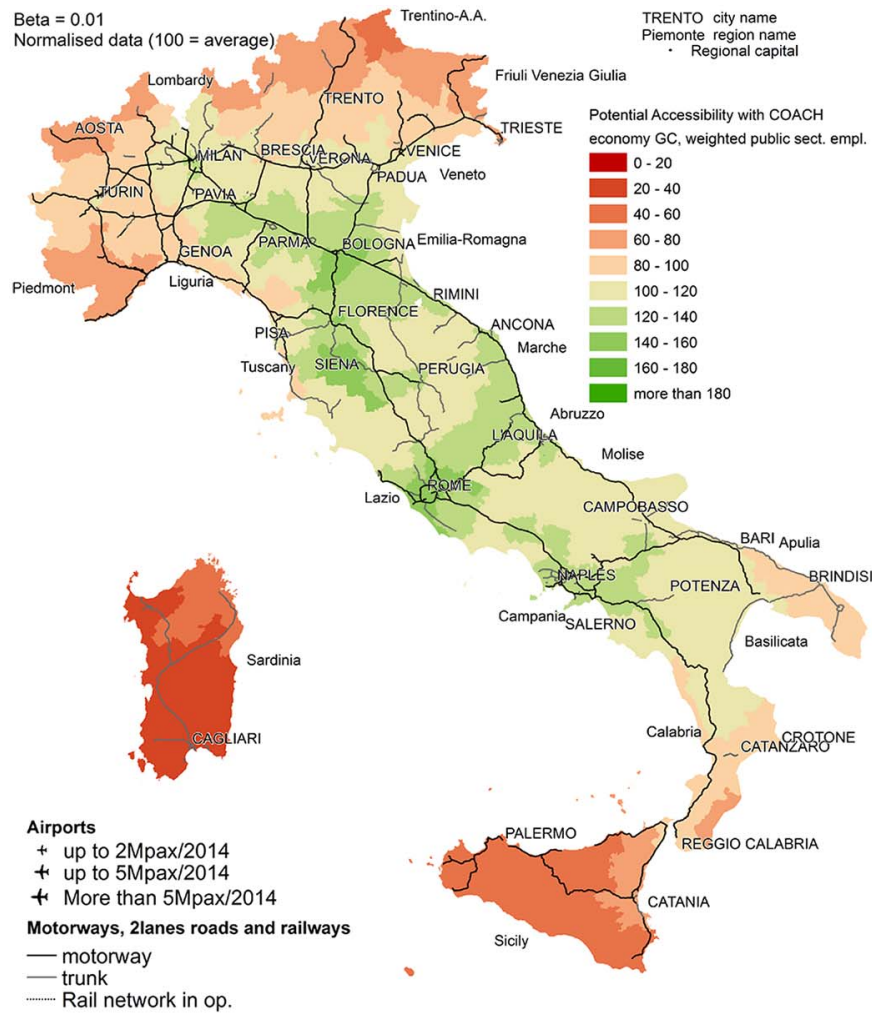

Fig. 5. (continued)

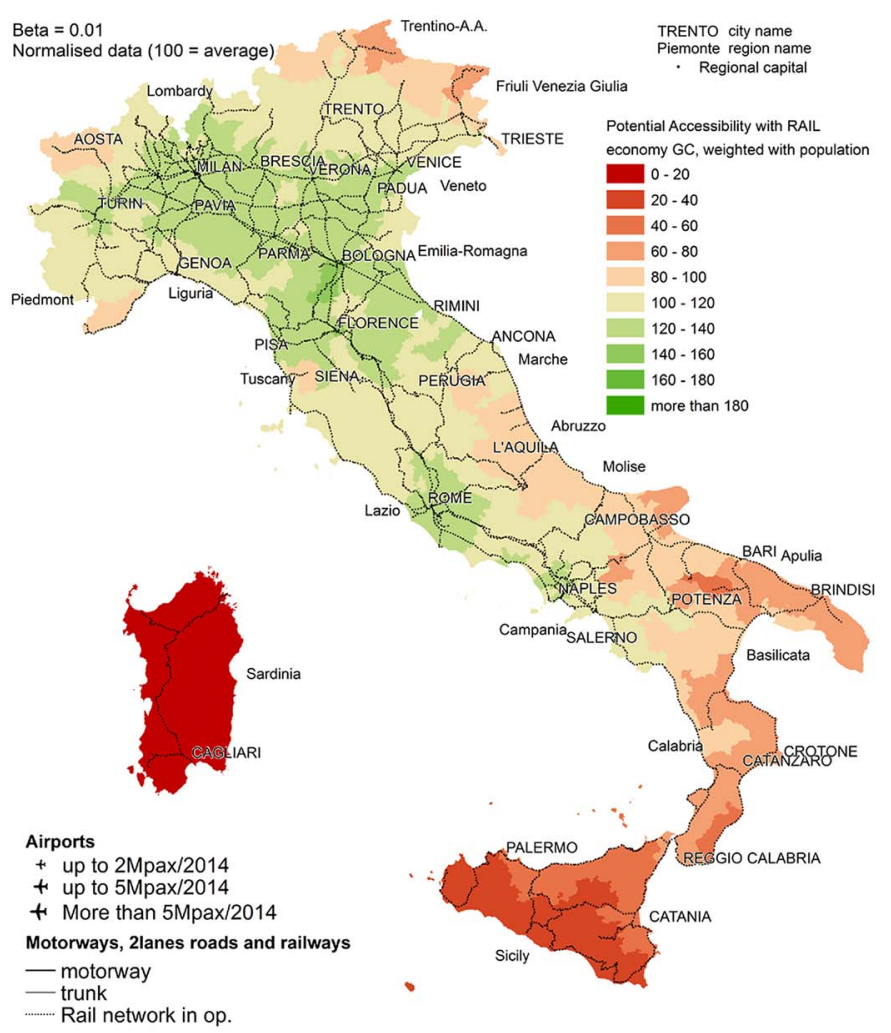

ranging from infinite to zero instead than from one to zero. This introduces a problem, as the transport model used is spatially very detailed in high population areas: we obtain values of generalised costs ranging from very low values for the local movements (for example from Milan city zone to surrounding zones) to very high values for the long distance trips (for example from Milan to southern regions' zones). To avoid local accessibility to dominate over the long-distance, we capped the negative power function for values below $10 €$ of generalised cost, the range where values go to infinite. Fig. 7 shows the results, using a parameter of alpha equal to 1,5 .

With respect to Fig. 4, centre, the areas with higher accessibility are the same (north, Rome, Naples), but with rather different diffusion. In particular, despite the correction, accessibility remains higher in correspondence with urban areas and quickly declines with remoteness. However, some effects remain visible, such as the effect of the highspeed corridor between Bologna and Rome or the catchment area of main southern airports such as Catania, Palermo or Cagliari.

We run sensitivity analysis for both functions and for four different parameters each. The results are presented in terms of ranking of the most and least accessible zones (Table 6).

Ranking is changing, but in all cases the top-10 and worst-10 accessible zones belong to a group of about 20. It means that, despite changes, top and worst accessible areas are more or less the same. It must also be noticed that for both functions (exponential decay and negative power), the top and worst zones for the higher parameters are just the most and least populated areas of the country. This shows that the parameters must be chosen carefully in order to avoid trivial results.

Concerning the exponential decay function, the lower is the beta parameter, the more the accessible areas belong to the highly infrastructure area comprised between the regions of Lombardy and EmiliaRomagna. Lower parameters, in fact, push the accessibility indicator towards its transport component (generalised cost, in this case), while high

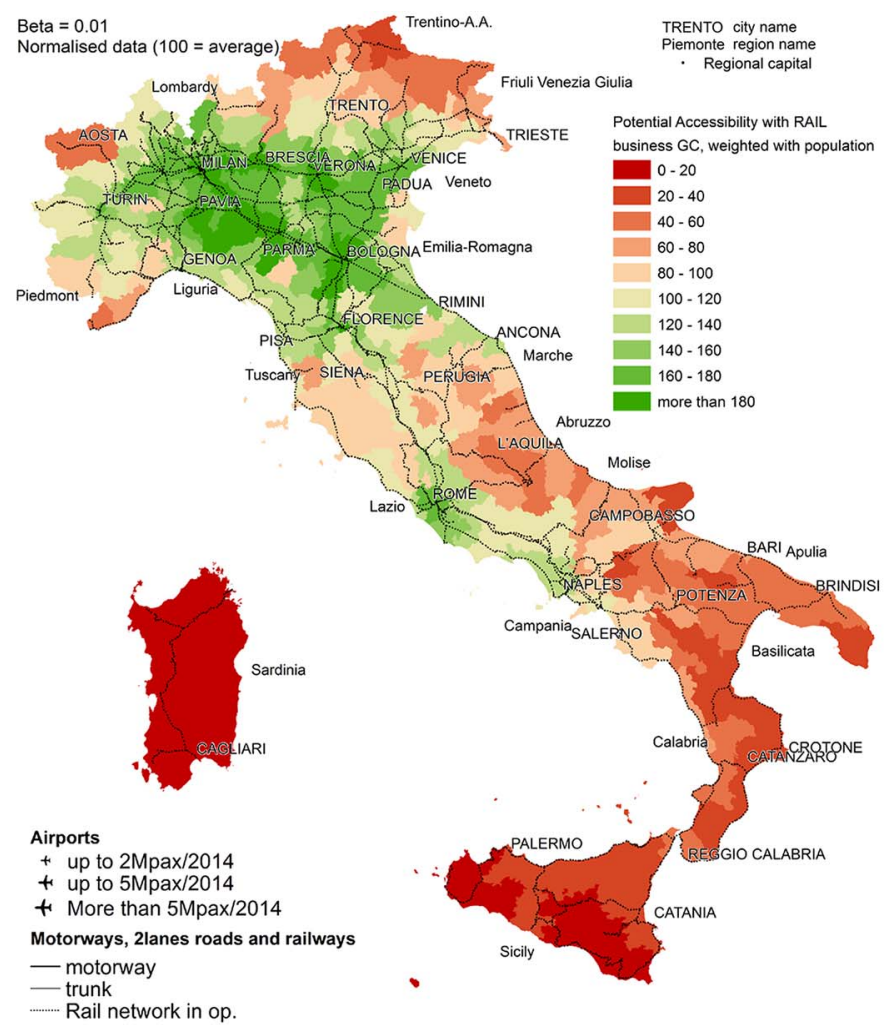

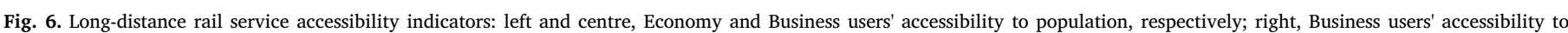
administrative centres. Source: our elaborations from transport model I-TraM (META-TRASPOL), based on 2013-2014 timetables. 


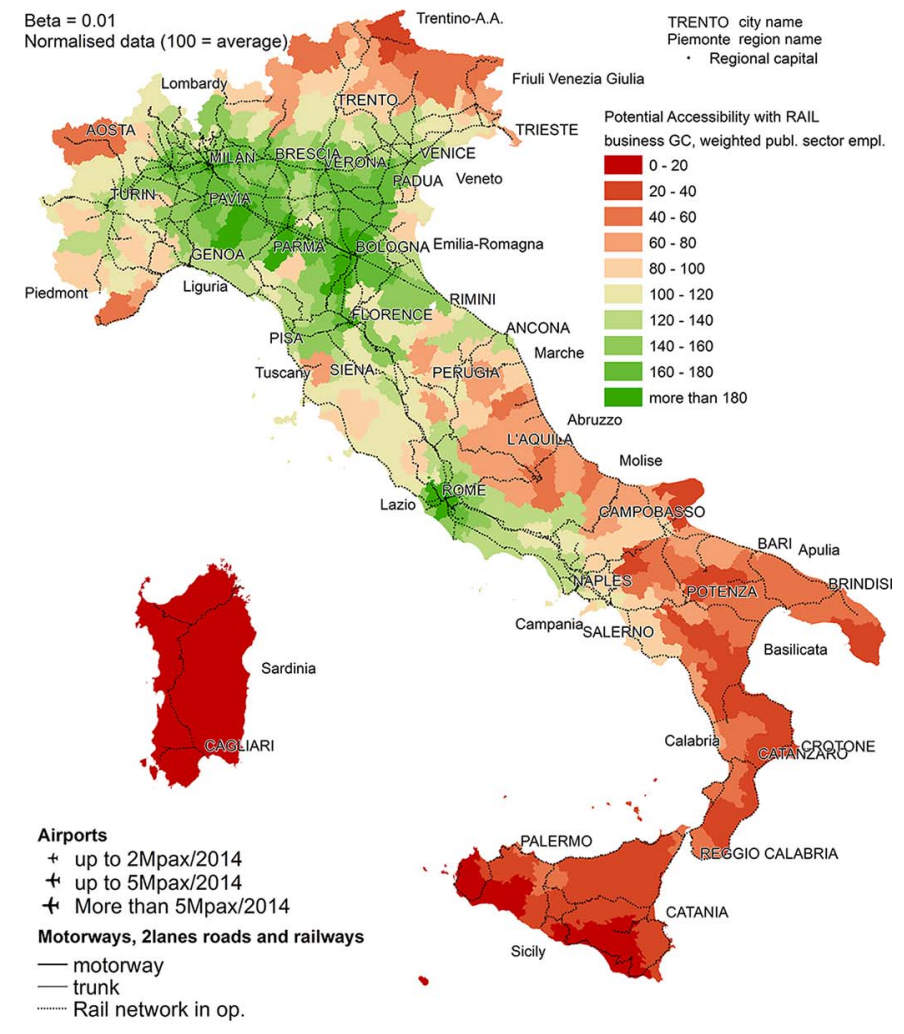

Fig. 6. (continued)

parameters towards its opportunity component (population, in this case).

\section{Methodological and policy considerations}

\subsection{Methodological considerations}

In this work, a common definition of accessibility was applied, together with some methodological innovations which make the analysis richer in revealing real-world conditions.

Firstly, we used a complete impedance function, based on generalised cost estimation including fares and interchange costs, rather than limiting it to travel time, which is not an acceptable simplification when studying long-distance transport.

Secondly, all calculations are based on a multimodal transport model, including rail and car transport, but also less-studied modes such as coach and air transport. In addition, the model does not just consider the supply, but also includes some market elements, with fares depending on the mode and on the actual level of competition. All of this makes the definition of generalised costs much more realistic because well linked to real transport conditions.

Also the spatial specification is highly detailed. The 371 zones in which Italy is divided correspond to about 800 sqkm and usually include one city only. Larger zones, for example at the provincial level, would have overestimated accessibility of suburban and rural territories, assuming for them the same accessibility of the provincial capitals, which is far from true. This detail allows to catch differences among main centres, served by long-distance services; secondary cities, with few long-distance services or needful of one interchange to reach main centres; dispersed areas, with no long-distance services and often no rail at all.

In order to provide a more realistic picture, accessibility measures were then differentiated according to two stylised travel profiles, namely Business and Economy travellers. A country's accessibility, in fact, is extremely different for users who do not own a car and are mindful of transport costs, when compared to those who have no cost limit but are very time-sensitive.

Of course results depend on the parameters of the decay functions. Sensitivity analysis is reasonably stable for extreme situations (top and worst accessible areas are clear), but the detailed ranking may change significantly. Consequently, accessibility maps found must be used just as a representation, under clearly defined conditions.

In the next section, we will comment how such measure can be used to assess the effect of transport policies in reducing geographical remoteness.

\subsection{Accessibility needs and Italian transport policies}

Transport policies and investments are not the rigid outcome of a totally rational and quantified process of evaluation, especially when considerations other than the sole transport dimension play a role (Albalate and Bel, 2012; Eliasson et al., 2015). As a consequence, the geography of accessibility does not depend only on geography and demography, but keeps the traces of political choices and technical limits in the networks' design.

A key element is how a country wants to be interconnected. One can simplify the question by means of two stylised and extreme visions on long-distance accessibility.

a. On the one hand, the policies of a country could focus on the connection of the main centres, leaving marginal areas unconnected. This approach looks at efficiency: connecting core areas gives better economic results for a given amount of resources, because this improves the performance of high-density corridors. Conversely, it will sharpen the gap between core-regions and marginal regions.

b. On the other hand, a country could opt for homogeneous accessibility, assuming that all long-distance trips are the same, irrespectively from purpose and distance. ${ }^{12}$ For example, any main city should be connected to the capital in no more than $x$ hours. ${ }^{13}$ This approach looks at territorial equity, trying to go beyond the geography by removing the differences. From the economic viewpoint, however, it will most likely give inefficient results, especially if depopulated areas are also the marginal ones and if the orography does not help.

Of course, real planning choices lie between these two extremes. To have a picture of that, we draw on a graph (Fig. 8) both distance-based and generalised cost-based accessibility scores of each zone. Points above the diagonal line present real accessibility higher than the one due to physical distance. For points below, the performance of the transport system is worse than what the simple distance would give.

Despite certain dispersion, the Italian accessibility trend is rather clear. The transport system tends to reduce the remoteness of geographically remote areas (left side). The centrality of core areas is then less extreme than their pure geographical position. For example, Milan's long-distance accessibility indicator is 132 (economy users, all modes, population weighted), while its accessibility based on the sole distance from attractors is much higher. On the opposite range, cities like Catania (the second Sicilian city) or Trieste (an important centre in the north-east) are similarly far from population cores, but their "gap" is reduced by the transport system. ${ }^{14}$

\footnotetext{
${ }^{12}$ By the way, this assumption is coherent with the negative exponential function (Choukroun, 1975).

${ }^{13}$ As an example, the Spanish high-speed rail originally adopted this criterion: despite traffic and dimension, any provincial capital must be connected to Madrid in $4 \mathrm{~h}$ (Albalate and Bel, 2011)

${ }^{14}$ It is worth mentioning that the slope of the distributions depends on the beta used, but the significant aspect is that the distribution is not linear and, over a certain accessibility, the relative advantage remains quite constant.
} 


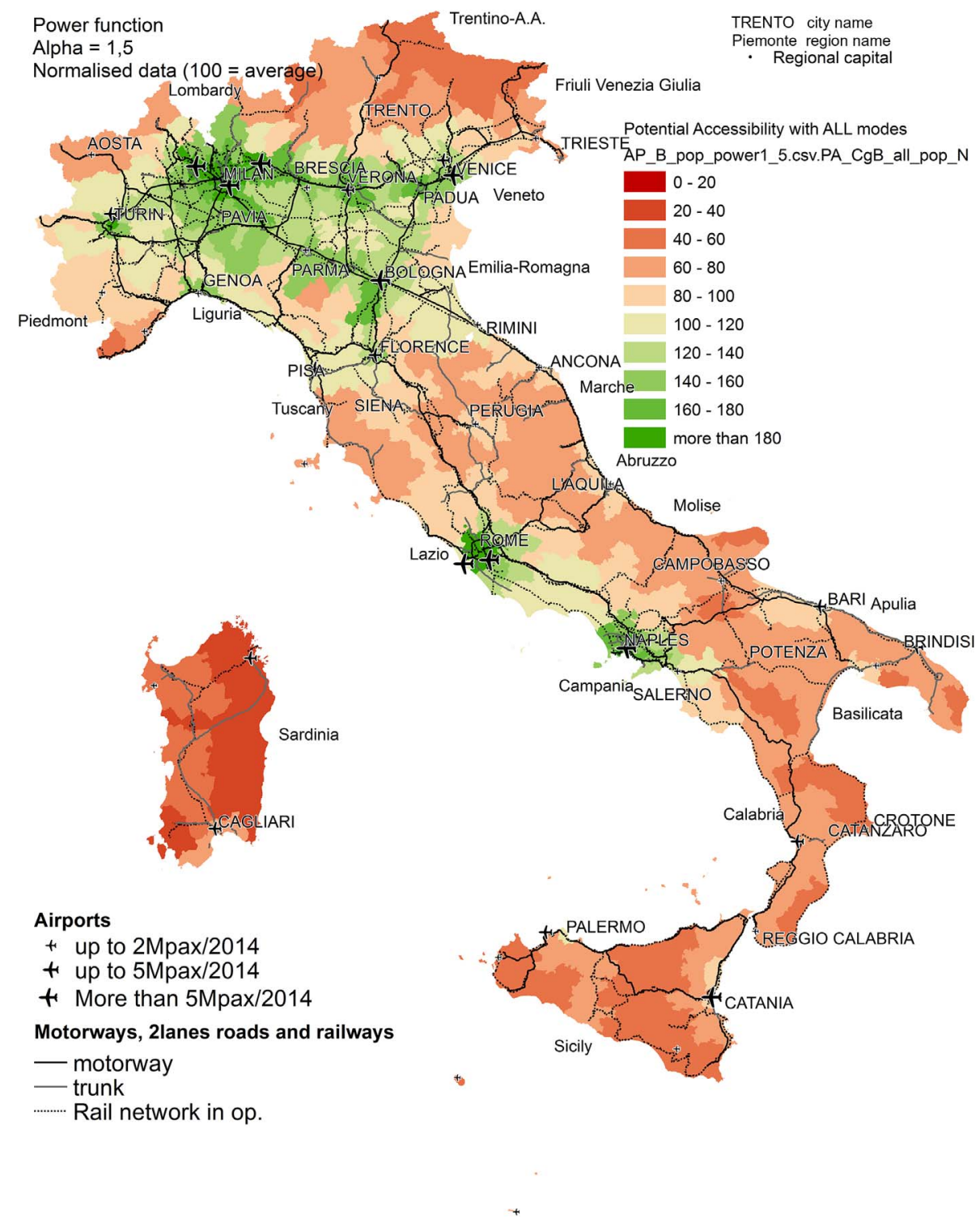

Fig. 7. Population weighted accessibility indicators using a negative power function (alpha $=1,5$ ). Business users, all modes. Source: our elaborations from transport model ITraM (META-TRASPOL), based on 2013-2014 timetables.

However, sharp differences exist between Economy users' accessibility and that of Business users. For Economy users, the distribution shows that the long-distance transport system has a visible role in reducing the unavoidable geographical disadvantages of southern and island regions, less populated and far from the core of the Italian population. The farthest zones have an indicator firmly below the national average in terms of physical distance, but always above it if the generalised cost is considered. This fact is not due to high-speed rail, still limited, but especially thanks to air and coach connections. Despite the undeniable differences between Italian zones and some severe situations of inaccessibility, we can affirm that a nationwide public transport system exists and it has a role in favouring long-distance transport.

To the contrary, Business distribution is significantly more similar to a distance-based one. This means that Business users' choices are too often dependent on cars, because other transport means are not equally effective, except for the highly accessible zones of the core like Milan or Rome. In this case, the effectiveness of the public transport system for business travel is much lower, and is limited to the main city pairs. Consequently, the "distance" of remote areas for business trips is such that it places a competitive disadvantage on such areas.

\section{Concluding remarks}

In the paper we used a transport supply model to feed a detailed measure of long-distance passenger potential accessibility in Italy. The aim of such measure is to highlight the complexity of the geography of accessibility at the country-scale and to comment it in terms of transport policies.

With respect to similar studies, one of the main novelties of the paper is the level of definition of the impedance function. It is not limited to travel time or distance, but considers all components of generalised cost, including frequency and fare levels depending on competition. Secondly, our accessibility considers all modes (rail, coach, air, car). We pointed out the contributions of each mode in defining the accessibility of one place, by means of single-mode accessibility maps and of multimodal ones.

It results that Italian geography of accessibility is complex. High accessibility areas are the highly populated north, but also Rome and Naples, forming a sort of dipole. The effect of main infrastructure is well visible, rising the accessibility of the main corridors with respect to peripheral areas. Southern Italy is by far less accessible than the north. The effect is the combination of geographical remoteness, lower population and of underperforming transport networks. However, the 
Table 6

Sensitivity analysis. Ranking of top and worst accessible zones.

\begin{tabular}{|c|c|c|c|c|}
\hline \multicolumn{5}{|c|}{ Top 10 - Exponential decay function } \\
\hline Beta & 0,1 & 0,03 & 0,01 & 0,005 \\
\hline 1 & Rome (city zone A) & Milano (prov zone B) & Milan (city) & Bologna (prov zone B) \\
\hline 2 & Milan (city) & Milan (city) & Milano (prov zone B) & Bologna (city) \\
\hline 3 & Naples (city) & Monza (city) & Monza (city) & Milan (city) \\
\hline 4 & Rome (city zone E) & Milano (prov zone E) & Bologna (prov zone B) & Milano (prov zone B) \\
\hline 5 & Rome (city zone D) & Milano (prov zone C) & Milano (prov zone E) & Monza (city) \\
\hline 6 & Rome (city zone C) & Varese (prov zone D) & Bologna (city) & Milano (prov zone E) \\
\hline 7 & Rome (city zone B) & Monza (prov zone $\mathrm{C}$ ) & Piacenza (city) & Piacenza (city) \\
\hline 8 & Milano (prov zone B) & Milano (prov zone F) & Milano (prov zone D) & Modena (city) \\
\hline 9 & Naples (prov zone D) & Milano (prov zone D) & Milano (prov zone F) & Bologna (prov zone $\mathrm{C}$ ) \\
\hline \multirow[t]{2}{*}{10} & Monza (city) & Milano (prov zone I) & Milano (prov zone C) & Milano (prov zone D) \\
\hline & \multicolumn{4}{|c|}{ Top 10 - Negative power function } \\
\hline Beta & 2 & 1,5 & 1 & 0,5 \\
\hline 1 & Rome (city zone A) & Rome (city zone A) & Milan (city) & Milan (city) \\
\hline 2 & Milan (city) & Milan (city) & Rome (city zone A) & Milano (prov zone B) \\
\hline 3 & Naples (city) & Milano (prov zone B) & Milano (prov zone B) & Monza (city) \\
\hline 4 & Milano (prov zone B) & Monza (city) & Monza (city) & Milano (prov zone E) \\
\hline 5 & Rome (city zone E) & Rome (city zone E) & Milano (prov zone E) & Milano (prov zone D) \\
\hline 6 & Rome (city zone D) & Rome (city zone D) & Milano (prov zone D) & Milano (prov zone F) \\
\hline 7 & Rome (city zone C) & Rome (city zone C) & Milano (prov zone C) & Milano (prov zone C) \\
\hline 8 & Rome (city zone B) & Rome (city zone B) & Rome (city zone D) & Monza (prov zone C) \\
\hline 9 & Monza (city) & Naples (city) & Rome (city zone E) & Bologna (prov zone B) \\
\hline 10 & Naples (prov zone D) & Monza (prov zone B) & Rome (city zone C) & Varese (prov zone D) \\
\hline
\end{tabular}

\begin{tabular}{|c|c|c|c|c|}
\hline \multicolumn{5}{|c|}{ Worst 10 - Exponential decay function } \\
\hline Beta & 0,1 & 0,03 & 0,01 & 0,005 \\
\hline 362 & Udine (prov zone F) & Crotone (city) & Oristano (city) & Sassari (prov zone E) \\
\hline 363 & Foggia (prov zone D) & Sassari (prov zone E) & Sassari (prov zone E) & Cagliari (prov zone $\mathrm{F}$ ) \\
\hline 364 & Pisa (prov zone $\mathrm{C}$ ) & Cagliari (prov zone $\mathrm{F}$ ) & Cagliari (prov zone F) & Nuoro (prov zone E) \\
\hline 365 & Trento (prov zone E) & Sassari (prov zone F) & Nuoro (prov zone B) & Oristano (city) \\
\hline 366 & Palermo (prov zone G) & Nuoro (city) & Nuoro (prov zone E) & Cagliari (prov zone E) \\
\hline 367 & Arzachena (prov zone D) & Nuoro (prov zone C) & Cagliari (prov zone D) & Nuoro (prov zone B) \\
\hline 368 & R. Emilia (prov zone B) & Nuoro (prov zone E) & Cagliari (prov zone E) & Cagliari (prov zone D) \\
\hline 369 & Belluno (prov zone $\mathrm{C}$ ) & Bolzano (prov zone D) & Nuoro (city) & Nuoro (city) \\
\hline 370 & Sondrio (prov zone C) & Cagliari (prov zone E) & Nuoro (prov zone C) & Nuoro (prov zone C) \\
\hline 371 & Cagliari (prov zone E) & Nuoro (prov zone D) & Nuoro (prov zone D) & Nuoro (prov zone D) \\
\hline & Worst 10 - Negative powe & function & & \\
\hline Beta & 2 & 1,5 & 1 & 0,5 \\
\hline 362 & Belluno (prov zone $\mathrm{C}$ ) & Cagliari (prov zone F) & Oristano (city) & Sassari (prov zone E) \\
\hline 363 & Sassari (prov zone E) & Sassari (prov zone F) & Cagliari (prov zone F) & Cagliari (prov zone F) \\
\hline 364 & Cagliari (prov zone D) & Sassari (prov zone E) & Sassari (prov zone E) & Oristano (city) \\
\hline 365 & Palermo (prov zone G) & Cagliari (prov zone D) & Cagliari (prov zone D) & Nuoro (prov zone E) \\
\hline 366 & Nuoro (city) & Nuoro (prov zone B) & Nuoro (prov zone B) & Nuoro (prov zone B) \\
\hline 367 & Nuoro (prov zone E) & Nuoro (prov zone E) & Nuoro (prov zone E) & Cagliari (prov zone E) \\
\hline 368 & Nuoro (prov zone B) & Nuoro (city) & Cagliari (prov zone E) & Cagliari (prov zone D) \\
\hline 369 & Nuoro (prov zone C) & Nuoro (prov zone C) & Nuoro (city) & Nuoro (city) \\
\hline 370 & Nuoro (prov zone D) & Cagliari (prov zone E) & Nuoro (prov zone C) & Nuoro (prov zone C) \\
\hline 371 & Cagliari (prov zone E) & Nuoro (prov zone D) & Nuoro (prov zone D) & Nuoro (prov zone D) \\
\hline
\end{tabular}

condition of inaccessibility is not homogeneous in all Southern Italy, as well as not all North is highly accessible. For example, Naples performs like Northern cities, despite its geographical disadvantage, thanks to excellent road and rail connections.

This fact is important in terms of transport policies. Comparing a distance-based accessibility with the cost-based one, we showed that Italian transport system is effective in reducing the natural geographical differences, making "far" places relatively less inaccessible and at the same time smoothing the relative advantage of core areas. This is the outcome of transport policies of the past which, far from being perfect,

aimed at providing a relatively fair level of supply in most of urban areas of the country.

\section{Acknowledgements}

Authors wish to thank the anonymous reviewers for their fruitful suggestions.

The research is part of the project "QUAINT", supported by the Italian Ministry of Education University and Research (MIUR) (RBSI14JR1Z), within the SIR programme (D.D. n. 197 del 23 gennaio 2014).

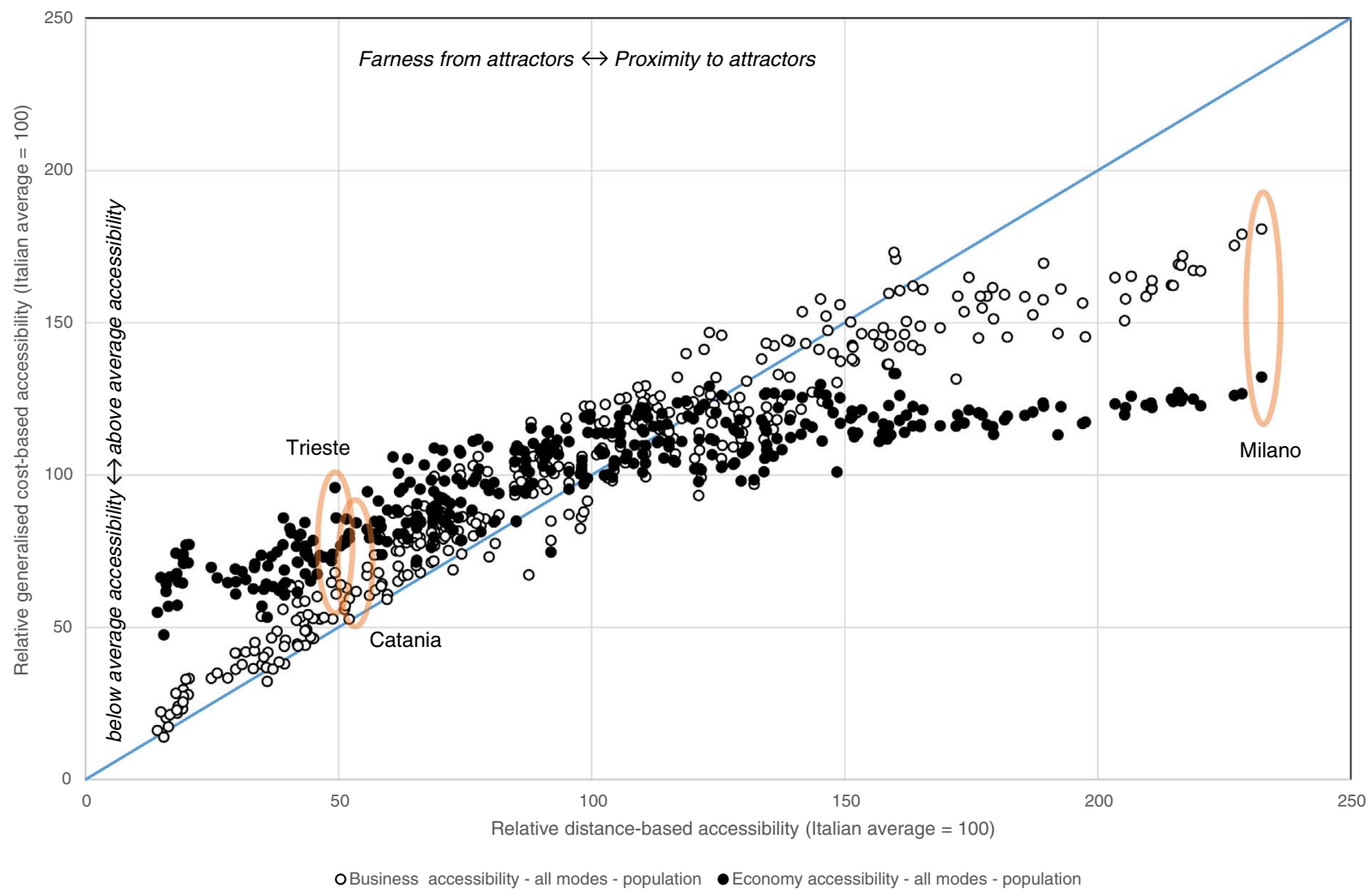

Fig. 8. Real accessibility (based on generalised cost) vs. distance-based accessibility. 


\section{References}

Alampi, D., Messina, G., 2011. Time-is-money: i tempi di trasporto come strumento per misurare la dotazione di infrastrutture in Italia. Banca d'Italia.

Albalate, D., Bel, G., 2011. Cuando la economía no importa: auge y esplendor de la alta velocidad en españa. J. Appl. Econ. 19 (55), 171.

Albalate, D., Bel, G., 2012. High-speed rail: lessons for policy makers from experiences abroad. Public Adm. Rev. 72 (3), 336-349.

Augustin, K., Gerike, R., Sanchez, M.J.M., Ayala, C., 2014. Analysis of intercity bus markets on long distances in an established and a young market: the example of the

US and Germany. Res. Transp. Econ. 48, 245-254.

Axhausen, K.W., Froelich, P., Tschopp, M., 2011. Changes in Swiss accessibility since 1850. Res. Transp. Econ. 31 (1), 72-80

Banca d'Italia, 2011. Le infrastrutture in Italia: dotazione, programmazione, realizzazione. Banca d'Italia, Rome, Italy.

Bentlage, M., Lüthi, S., Thierstein, A., 2013. Knowledge creation in German agglomerations and accessibility-an approach involving non-physical connectivity. Cities 30,

47-58.

Beria, P., Giove, M., Miele, M., 2012. A comparative analysis of assessment approaches. six cases from Europe. International Journal of Transport Economics 185-217 xxxix.

Beria, P., Grimaldi, R., Debernardi, A., Ferrara, E., Laurino, A., 2014. Spatial and scenario analyses of long distance coach transport in Italy. In: Munich Personal RePEc

Archive, . http://mpra.ub.unimuenchen.de/54739/.

Beria, P., Debernardi, A., Grimaldi, R., Ferrara, E., Laurino, A., Bertolin, A., 2015. From infrastructure to service: mapping long-distance passenger transport in Italy. J. Maps 1-9.

Brödner, B., Schwarze, B., Spiekermann, K., 2014. ESPON atlas. In: Mapping European Territorial Structures and Dynamics. Urban and Regional Research (S \& W),

Dortmund, Germany.

Cascetta, E., Cartenì, A., Montanino, M., 2013. A new measure of accessibility based on perceived opportunities. Procedia. Soc. Behav. Sci. 87, 117-132.

Choukroun, J.M., 1975. A general framework for the development of gravity-type trip distribution models. Reg. Sci. Urban Econ. 5 (2), 177-202.

CNIT, 2013. Conto Nazionale delle Infrastrutture e dei Trasporti-Anni 2011-2012. Istituto Poligrafico e Zecca dello Stato SpA, Rome, Italy.

Condeço-Melhorado, A., Gutiérrez, J., García-Palomares, J.C., 2011. Spatial impacts of road pricing: accessibility, regional spillovers and territorial cohesion. Transp. Res. A

Policy Pract. 45 (3), 185-203.

Condeço-Melhorado, A.M., Demirel, H., Kompil, M., Navajas, E., Christidis, P., 2016. The impact of measuring internal travel distances on self-potentials and accessibility. Eur. J. Transp. Infrastruct. Res. 16 (2), 300-318.

De Montis, A., Caschili, S., Chessa, A., 2011. Spatial complex network analysis and accessibility indicators: the case of municipal commuting in Sardinia, Italy. Eur. J. Transp. Infrastruct. Res. 11 (4), 405-419.

Dewulf, B., Neutens, T., Vanlommel, M., Logghe, S., De Maeyer, P., Witlox, F., DeWeerdt, Y., Van de Weghe, N., 2015. Examining commuting patterns using Floating Car Data and circular statistics: exploring the use of new methods and visualizations to study travel times. J. Transp. Geogr. 48, 41-51.

Duran-Fernandez, R., Santos, G., 2014. A regional model of road accessibility in Mexico: accessibility surfaces and robustness analysis. Res. Transp. Econ. 46, 55-69. Eddington, R., 2006. The Eddington Transport Study-The case for action-Sir Rod Eddington's advice to Government-December 2006.

El-Geneidy, A., Levinson, D., 2011. Place rank: valuing spatial interactions. Networks and Spatial Economics 11 (4), 643-659.

Eliasson, J., Borjesson, M., Odeck, J., Welde, M., 2015. Does benefit-cost efficiency influence transport investment decisions. JTEP 49, 377-396.

European Commission, 2007. Regions in the European Union - Nomenclature of Territorial Units for Statistics - NUTS 2006/EU27. Office for Official Publications of

the European Communities, Luxembourg.

Fotheringham, A.S., O'Kelly, M.E., 1989. Spatial Interaction Models: Formulations and Applications. Kluver Academic Publishers, Dordrecht (NL)

Fransen, K., Neutens, T., Farber, S., De Maeyer, P., Deruyter, G., Witlox, F., 2015 Identifying public transport gaps using time-dependent accessibility levels. J. Transp. Geogr. 48, 176-187.

Geertman, S.C.M., Ritsema van Eck, J., 1995. GIS and models of accessibility potential: an application in planning. Int. J. Geogr. Inf. Syst. 9, 67-80.

Geurs, K.T., Ritsema van Eck, J.R., 2003. Evaluation of accessibility impacts of land-use scenarios: the implications of job competition, land-use, and infrastructure developments for the Netherlands. Environ. Plann. B. Plann. Des. 30 (1), 69-88.

Geurs, K.T., Van Eck, J.R.R., 2001. Accessibility Measures: Review and Applications. National Institute of Public Health and the Environment, Bilthoven.

Geurs, K.T., van Wee, B., 2004. Accessibility evaluation of land-use and transport strategies: review and research directions. J. Transp. Geogr. 12 (2), 127-140.

Geurs, K.T., Krizek, K.J., Reggiani, A., 2012. Accessibility analysis and transport planning: an introduction. In: Accessibility Analysis and Transport Planning, Challenges for Europe and North America. Edward Elgar Publishing.

Grimaldi, R., Augustin, K., Beria, P., 2017. Intercity coach liberalisation. The cases of Germany and Italy. In: Transportation Research Procedia, (forthcoming).

Gutiérrez, J., Urbano, P., 1996. Accessibility in the European Union: the impact of the trans-European road network. J. Transp. Geogr. 4 (1), 15-25.

Halás, M., Klapka, P., Kladivo, P., 2014. Distance-decay functions for daily travel-to-work flows. J. Transp. Geogr. 35, 107-119.

Handy, S.L., Niemeier, D.A., 1997. Measuring accessibility: an exploration of issues and alternatives. Environ. Plan. A 29 (7), 1175-1194.

Haynes, R., Lovett, A., Sünnenberg, G., 2003. Potential accessibility, travel time, and consumer choice: geographical variations in general medical practice registrations in
Eastern England. Environ. Plan. A 35, 1733-1750. http://dx.doi.org/10.1068/ a35165.

Holl, A., 2007. Twenty years of accessibility improvements. The case of the Spanish motorway building programme. J. Transp. Geogr. 15 (4), 286-297.

ISTAT, 2013. Atlante statistico delle infrastrutture. In: Aggiornamento 2013. ISTAT, Rome, Italy.

Jacobs-Crisioni, C., e Silva, F.B., Lavalle, C., Baranzelli, C., Barbosa, A., Castillo, C.P., 2016. Accessibility and territorial cohesion in a case of transport infrastructure im-provements with changing population distributions. Eur. Transp. Res. Rev. 8 (1), 1-16.

Jiao, J., Wang, J., Jin, F., Dunford, M., 2014. Impacts on accessibility of China's present and future HSR network. J. Transp. Geogr. 40, 123-132.

Karampela, S., Kizos, T., Spilanis, I., 2014. Accessibility of islands: towards a new geography based on transportation modes and choices. Island Studies Journal 9 (2), 293-306.

Keeble, D., Owens, P.L., Thompson, C., 1982. Regional accessibility and economic potential in the European Community. Reg. Stud. 16 (6), 419-432.

Koopmans, C., Groot, W., Warffemius, P., Annema, J.A., Hoogendoorn-Lanser, S., 2013. Measuring generalised transport costs as an indicator of accessibility changes over time. Transp. Policy 29, 154-159.

Lattarulo, P., 2009. Dotazione infrastrutturale e investimenti pubblici. IRPET, Florence, Italy.

Leonardi, G., 1985. Equivalenza asintotica tra la teoria delle utilità casuali e la massimizzazione dell'entropia. In: Reggiani, A. (Ed.), Territorio e trasporti. Modelli ma-

tematici per l'analisi e la pianificazione. F.Angeli, Milano, pp. 29-66.

Martín, J.C., Reggiani, A., 2007. Recent methodological developments to measure spatial interaction: synthetic accessibility indices applied to high-speed train investments. Transp. Rev. 27 (5), 551-571.

Martínez, L.M., Viegas, J.M., 2013. A new approach to modelling distance-decay functions for accessibility assessment in transport studies. J. Transp. Geogr. 26, 87-96. MCC 2003. Talkin' bout a revolution. In: Il Sistema dei trasporti in Italia. Capitalia Gruppo Bancario, Rome, Italy.

Ministero dei Trasporti, 2001. Piano Generale Dei Trasporti e della Logistica. Ministero dei Trasporti e della Navigazione, Rome, Italy.

Ortega, E., Mancebo, S., Otero, I., 2011. Road and railway accessibility atlas of Spain. J. Maps 7 (1), 31-41.

Ortega, E., López, E., Monzón, A., 2012. Territorial cohesion impacts of high-speed rail at different planning levels. J. Transp. Geogr. 24, 130-141.

Ortúzar, J., Willumsen, L.G., 1990. Modelling Transport. John Wiley \& Sons, Chichester.

Östh, J., Reggiani, A., Galiazzo, G., 2015. Spatial economic resilience and accessibility: a joint perspective. Comput. Environ. Urban. Syst. 49, 148-159.

Páez, A., Scott, D.M., Morency, C., 2012. Measuring accessibility: positive and normative implementations of various accessibility indicators. J. Transp. Geogr. 25, 141-153.

Reggiani, A., Martín, J.C., 2011. Guest editorial: new frontiers in accessibility modelling: an introduction. Networks and Spatial Economics 11 (4), 577-580.

Reggiani, A., Bucci, P., Russo, G., 2011a. Accessibility and network structures in the german commuting. Networks and Spatial Economics 11 (4), 621-641.

Reggiani, A., Bucci, P., Russo, G., 2011b. Accessibility and impedance forms: empirical applications to the german commuting network. Int. Reg. Sci. Rev. 34, 230-252. http://dx.doi.org/10.1177/0160017610387296.

Rosik, P., Steppniak, M., Komornicki, T., 2015. The decade of the big push to roads in Poland: impact on improvement in accessibility and territorial cohesion from a policy perspective. Transp. Policy 37, 134-146.

Schürmann, C., Talaat, A., 2000. Towards a European Peripherality Index. In: Final Report, Report for General Directorate XVI Regional Policy of the European Commission. Berichte aus dem Inst. f $\{\ddot{u}\} \mathrm{r}$ Raumplan. der Univ, Dortmund 53.

Schürmann, C., Spiekermann, K., Wegener, M., 1997. Accessibility indicators: model and report. In: SASI Deliverable D5, Report to the European Commission. Institute für Raumplanung, Universität Dortmund, Dortmund.

Skov-Petersen, H., 2001. Estimation of Distance-decay parameters - GIS-based indicators of recreational accessibility. In: Bjørke, J.T., Tveite, H. (Eds.), ScanGIS 2001, Proceedings of the 8th Scandinavian Research Conference on Geo-graphical Information Science. Aas, Norway, June 24-27 2001.

Spiekermann, K., Schürmann, C., 2007. Update of Selected Potential Accessibility Indicators. (Final Report).

Spiekermann, K., Wegener, M., Květoň, V., Marada, M., Schürmann, C., Biosca, O., Ulied Segui, A., Antikainen, H., Kotavaara, O., Rusanen, J., Bielańska, D., Fiorello, D., Komornicki, T., Rosik, P., Stepniak, M., 2014. TRACC transport accessibility at regional/local scale and patterns in Europe. In: Final Report, ESPON Applied Re-search, (forthcoming)

Stępniak, M., Rosik, P., 2013. Accessibility improvement, territorial cohesion and spillovers: a multidimensional evaluation of two motorway sections in Poland. J. Transp.

Geogr. 31, 154-163. http://dx.doi.org/10.1016/j.jtrangeo.2013.06.017.

Stępniak, M., Rosik, P., 2015. The impact of data aggregation on potential accessibility values. In: Geoinformatics for Intelligent Transportation. Springer International Publishing, pp. 227-240.

Stepniak, M., Rosik, P., Komornicki, T., 2013. Accessibility patterns: Poland case study. Eur. XXI 24, 77-93. http://dx.doi.org/10.7163/Eu21.2013.24.6.

Uniontrasporti, 2011. Rapporto sullo stato delle infrastrutture in Italia: criticità di oggi, priorità di domani. Unioncamere, Rome, Italy.

Vandenbulcke, G., Steenberghen, T., Thomas, I., 2009. Mapping accessibility in Belgium:

a tool for land-use and transport planning? J. Transp. Geogr. 17 (1), 39-53. Vickerman, R., Spiekermann, K., Wegener, M., 1999. Accessibility and economic development in Europe. Reg. Stud. 33 (1), 1-15.

van Wee, B., 2016. Accessible accessibility research challenges. J. Transp. Geogr. 51, 9-16.

Wilson, A.G., 1970. Entropy in Urban and Regional Modelling. Pion, London.

Wilson, A.G., 1974. Urban and Regional Models in Geography and Planning. Wiley, Chichester. 